\title{
Super Rice With High Sink Activities Has Superior Adaptability to Low Filling Stage Temperature
}

\author{
Congshan Xu ${ }^{1,2,3}$, Fei Yang ${ }^{1}$, Xinao Tang ${ }^{1,2,3}$, Bo Lu ${ }^{1,2,3}$, Ziyu Li ${ }^{1,2,3}$, Zhenghui Liu ${ }^{1,2,3,4}$, \\ Yanfeng Ding ${ }^{1,2,3,4}$, Chao Ding ${ }^{5}$ and Ganghua $\mathrm{Li}^{1,2,3,4 *}$ \\ ${ }^{1}$ College of Agronomy, Nanjing Agricultural University, Nanjing, China, ${ }^{2}$ Key Laboratory of Crop Physiology Ecology and \\ Production Management, Ministry of Agriculture, Nanjing, China, ${ }^{3}$ Jiangsu Collaborative Innovation Center for Modern Crop \\ Production, Nanjing, China, ${ }^{4}$ National Engineering and Technology Center for Information Agriculture, Nanjing, China, \\ ${ }^{5}$ Institute of Food Crops, Jiangsu Academy of Agricultural Sciences, Nanjing, China
}

OPEN ACCESS

Edited by:

Yingfang Zhu,

Henan University, China

Reviewed by:

Weiqiang Li,

RIKEN, Japan

Hai Du,

Southwest University, China

${ }^{*}$ Correspondence:

Ganghua L

Igh@njau.edu.cn

Specialty section:

This article was submitted to Plant Physiology,

a section of the journal

Frontiers in Plant Science

Received: 22 June 2021 Accepted: 02 September 2021

Published: 27 October 2021

Citation:

X U C, Yang F, Tang X, Lu B, Li Z, Liu Z,

Ding Y, Ding C and Li G (2021) Super Rice With High Sink Activities Has Superior Adaptability to Low Filling

Stage Temperature.

Front. Plant Sci. 12:729021 doi: 10.3389/fp/s.2021.729021
To investigate the differential responses of super rice grain filling to low filling stage temperature (LT) and the regulative effect of nitrogen panicle fertilizer (NPF), physiological and molecular experiments were conducted with two super rice varieties (Nanjing 7th: N7 and Nanjing 9108th: N9108) on two different filling stage temperature treatments implemented by applying two sowing dates [Normal filling stage temperature (CK): Sowed on May 30, $\mathrm{T}_{\text {mean }}=24.7^{\circ} \mathrm{C}$ and low filling stage temperature (LT): Sowed on July $1, T_{\text {mean }}=20.3^{\circ} \mathrm{C}$, and two NPF levels $\left(0\right.$ and $150 \mathrm{~kg} \mathrm{~N}$ ha $\left.^{-1}\right)$. In this study, LT, NPF, and simultaneous LT and NPF treatments suppressed the grain filling in all varieties with different levels. Under LT or NPF treatments, the reduction of grain weight, seed setting rate, and filling rate were closely associated with suppressed starch biosynthesis rate in inferior seeds, suggesting that reduced starch biosynthesis rate, expression, and activities of enzymes encoded by related genes, Floury endosperm-4 (FLO4), Starch branching enzyme-I (SBE1), and Starch phosphorylase-L (PHO-I), were responsible for the grain filling reduction. Under LT or NPF treatments, significantly higher grain filling rates and lower variance were found in N9108 compared to that in N7, which were closely related to their higher starch biosynthesis ability, related gene expression, and enzymes activities. One of the probable explanations of the grain filling difference was the variation in the relative amount of key regulative hormones, Abscisic acid (ABA) and 1-aminocyclopropane-1-carboxylic acid (ACC). These results raise a possibility that super rice with higher sink activities has superior adaptability to LT and NPF due to their higher sink activities.

Keywords: super rice, grain filling, temperature, sowing date, sink activity

\section{INTRODUCTION}

Rice (Oryza sativa L.) is one of the staple food crops in China. It has made a great contribution to China's national economy (Khush, 2013; National Bureau of Statistics of China, 2015). Rapid population growth and economic development are growing pressures for an increase in food production (Zhang et al., 2007). However, the increase in rice yield has declined since the mid1980s, as reflected by the sharp drop in the rate of annual yield increase from $2.7 \%$ in the 1980 s to $1.1 \%$ in the 1990s (Horie et al., 2005). To further increase yield, breeding efforts have expanded the yield sink capacity (the maximum size of sink organs to be harvested) mainly by increasing the number of spikelets per panicle (Kato et al., 2007). As a result, cultivars with large panicles or extra-heavy panicle types with numerous spikelets per panicle have 
become available, such as hybrid rice and "super" rice or "super" hybrid rice in China (Cheng et al., 2007; Peng et al., 2008). However, some past research showed that these varieties can hardly realize their yield potential due to their poor grain filling in the field (Peng et al., 1999; Yang et al., 2002; Ao et al., 2008; Yang, 2010). Different grain filling and yield performance were found, in some super rice varieties, with similar panicle architecture and growth duration, suggesting that the panicle architecture and growth duration were not the major limitations of poor grain filling (Wang et al., 2002; Cheng et al., 2007; Zhang et al., 2007). The sink activity, which is represented by starch synthesis ability, could be the limiting factor of rice grain filling and final yield establishment (Venkateswarlu and Visperas, 1987; Ho, 1988; Liang et al., 2001).

Slow grain-filling rate and low grain weight were proved to be attributed to two major factors: the limitation of carbohydrate supplement and suppression of sink activities (Yang and Zhang, 2010). Previous studies showed that the supply of carbohydrates could be altered by abiotic stress conditions and was also closely related to the sucrose-starch conversion by controlling the concentration of the major substrate of the conversion (Yang and Zhang, 2010). Lower concentrations of soluble carbohydrate in the grain were found in response to abiotic stresses conditions and could be responsible for the final grain weight reduction (Yang and Zhang, 2010). The starch synthesis ability of rice grains was also positively correlated with the grain filling rate, and further controls the final grain weight (Wang et al., 2008; Yang and Zhang, 2010). The starch synthesis can be controlled by several factors, such as Floury endosperm-4 (FLO4), Starch branching enzyme-I (SBE1), and Starch phosphorylase-L (PHOl) (Yoshida and Hara, 1977; Yang et al., 2001a; Zhao et al., 2004; Zhu et al., 2004; Duan and Sun, 2005). Therefore, the difference in the sink activity of rice grains could be explained by exploring the activity and expression of the target enzyme in the grain filling stage. Previous studies always focused on the gap between superior and inferior seeds of different varieties (Yang et al., 2008). However, the difference in filling rates of superior and inferior seeds is also a major contributor in grain yield and weight establishment.

With the rapid development of agriculture and the change of planting structure, the traditional manual transplanting mode has been replaced by mechanic transplanting (Peng, 2016; Zou and Huang, 2018). This can be observed in the middle and lower reaches of the Yangtze River, known as the major ricewheat rotation cropping region where lower sowing dates have occurred due to traditional manual transplanting mode being gradually replaced by mechanized transplanting (Xing et al., 2016). As a result, the late sowing date postpones the rice growth duration, which leads to a lower temperature, suppressed rice filling, and reduced grain weight, which consequently produces a reduced grain yield (Qiu et al., 2016). Low temperature stress in the reproductive stage was correlated to the suppression of gene expression related to starch accumulation (Sipaseuth et al., 2007; Jacobs and Pearson, 2010). It was also correlated to further reducing the biosynthesis of starch in different varieties. However, the response of rice, especially "super" rice, and underlying physiological mechanism were still not clear. Sowing time is always given great importance in fields to ensure that rice plants avoid low-temperature stress and in completing the grain filling process earlier (Van Loon et al., 2014). Many previous studies have investigated changes in grain filling in response to different temperatures during the reproductive stage. However, most of those studies were carried out in a controlled greenhouse. Greenhouse studies are unlikely to accurately imitate the long-term cultivation in the field conditions and, therefore, show discrepant results from field studies (Patindol et al., 2015). Some previous studies also adopted this method to mimic low temperature treatment in the field. Wang et al. (2015) performed a field study to investigate the effects of environmental temperature on rice starch accumulation. On the other hand, many previous studies showed that grain filling was mainly controlled by reproductive stage temperature, while light treatment only slightly suppressed the grain filling (Yoshida and Hara, 1977). Thus, we adopted similar sowing dates to mimic the variation of reproductive stage LT stress. The plant hormones that mediate spikelet development, especially ethylene and abscisic acid (ABA), play important roles in regulating grain filling. A higher rate of ethylene evolution in developing seeds suppresses the expression of most starch-synthesis genes and inhibits the activities of starch synthesis-related enzymes which thus leads to a low grain-filling rate (Yang et al., 2006; Zhu et al., 2011; Panda et al., 2018). The 1-aminocyclopropane-1carboxylic acid (ACC), as the precursor of ethylene biosynthesis, was found to be closely correlated with ethylene content, and could significantly downregulate the grain filling rate (Yang et al., 2006). ABA acts as a sensitive signal during abiotic stress in plants, and its role in grain filling is complicated (Wang et al., 2019). It is notable that ABA plays a key role in grain filling by regulating the sink activity. In addition, it functions in a dose-dependent manner (Wang et al., 2015). An appropriate concentration of ABA can enhance the activities of enzymes involved in sucrose cleaving and starch synthesis and increase the expression of genes related to starch metabolism (Wang et al., 2015). Davies (1995) proposed that plant hormones can act either synergistically or antagonistically and is the balance between promoting and inhibiting agents that ultimately determines the path of plant growth and development. Yang et al. (2006) found that the grain filling rate was not only correlated with the concentration of ABA and ethylene, but also with the ratio of $\mathrm{ABA}$ and $\mathrm{ACC}$. In this study, the metabolite content dynamics, $\mathrm{ACC}$ and $\mathrm{ABA}$, were also measured to find out their regulative mechanism under low temperature condition.

Nitrogen was always adopted as one of the most important regulators of rice growth, grain yield, and quality (Kirk et al., 1997). Nitrogen panicle fertilizer (NPF) is always necessary for the field conditions to enhance the spikelet number, whereas the seed setting rate was suppressed (Ding et al., 2003, 2010, 2014; Zhang et al., 2007). Some studies showed that rational utilization of nitrogen fertilizer improved the activity of grain starch synthesis (Zhang et al., 2008). Other studies showed poor grain filling and no increase in the number of grains per panicle simultaneously (Mae, 1997; Yang A. et al., 2004; Samonte et al., 2006). Moreover, high nitrogen levels in grains reduced the carbohydrate accumulation in plant source organs, 
TABLE 1 | The mean daily temperature $\left(T_{\text {mean }},{ }^{\circ} \mathrm{C}\right)$, minimum temperature $\left(T_{\min },{ }^{\circ} \mathrm{C}\right)$, maximum temperature $\left(T_{\max },{ }^{\circ} \mathrm{C}\right)$, and accumulated temperature $\left(\mathrm{T}_{\text {accumulated }},{ }^{\circ} \mathrm{C}\right)$ in response to CK and LT treatments of 2 varieties (N7 and N9108) in 2016 and 2017.

\begin{tabular}{|c|c|c|c|c|c|c|c|c|c|}
\hline \multirow[t]{4}{*}{ Stage } & \multirow[t]{4}{*}{ Parameters } & \multicolumn{8}{|c|}{ Year } \\
\hline & & \multicolumn{4}{|c|}{2016} & \multicolumn{4}{|c|}{2017} \\
\hline & & \multicolumn{2}{|c|}{ CK } & \multicolumn{2}{|c|}{$\mathbf{L T}$} & \multicolumn{2}{|c|}{ CK } & \multicolumn{2}{|c|}{ LT } \\
\hline & & N9108 & N7 & N9108 & N7 & N9108 & N7 & N9108 & N7 \\
\hline \multirow[t]{4}{*}{ Transplanting } & $\mathrm{T}_{\text {mean }}\left({ }^{\circ} \mathrm{C}\right)$ & 23.37 & 23.37 & 26.76 & 26.76 & 24.25 & 24.25 & 27.12 & 27.12 \\
\hline & $\mathrm{T}_{\max }\left({ }^{\circ} \mathrm{C}\right)$ & 29.32 & 29.32 & 30.08 & 30.08 & 28.77 & 28.77 & 31.95 & 31.95 \\
\hline & $\mathrm{T}_{\min }\left({ }^{\circ} \mathrm{C}\right)$ & 20.02 & 20.02 & 23.99 & 23.99 & 19.19 & 19.19 & 23.17 & 23.17 \\
\hline & $\mathrm{T}_{\text {accumulated }}\left({ }^{\circ} \mathrm{C}\right)$ & 253.33 & 253.33 & 321.07 & 321.07 & 285.01 & 285.01 & 342.45 & 342.45 \\
\hline \multirow[t]{4}{*}{ Tillering } & $\mathrm{T}_{\text {mean }}\left({ }^{\circ} \mathrm{C}\right)$ & 26.38 & 26.98 & 30.99 & 31.32 & 27.67 & 27.97 & 31.52 & 31.54 \\
\hline & $\mathrm{T}_{\max }\left({ }^{\circ} \mathrm{C}\right)$ & 33.98 & 33.98 & 33.98 & 33.98 & 34 & 34.22 & 34.22 & 34.22 \\
\hline & $\mathrm{T}_{\min }\left({ }^{\circ} \mathrm{C}\right)$ & 20.37 & 20.37 & 27.23 & 27.23 & 21.29 & 21.29 & 28.12 & 28.12 \\
\hline & $\mathrm{T}_{\text {accumulated }}\left({ }^{\circ} \mathrm{C}\right)$ & 612.33 & 633.79 & 573.08 & 555.12 & 671.27 & 718.73 & 602.42 & 581.5 \\
\hline \multirow[t]{4}{*}{ Panicle initiation } & $\mathrm{T}_{\text {mean }}\left({ }^{\circ} \mathrm{C}\right)$ & 31.51 & 30.53 & 27 & 27.23 & 30.59 & 29.64 & 26.21 & 26.44 \\
\hline & $\mathrm{T}_{\max }\left({ }^{\circ} \mathrm{C}\right)$ & 35.25 & 35.25 & 33.6 & 33.6 & 34.22 & 34.22 & 32.62 & 32.62 \\
\hline & $\mathrm{T}_{\min }\left({ }^{\circ} \mathrm{C}\right)$ & 26.52 & 24.16 & 22.6 & 22.6 & 25.75 & 23.46 & 21.94 & 21.94 \\
\hline & $\mathrm{T}_{\text {accumulated }}\left({ }^{\circ} \mathrm{C}\right)$ & 660.52 & 670.65 & 549.35 & 557.1 & 638.18 & 647.97 & 534.91 & 542.45 \\
\hline \multirow[t]{4}{*}{ Grain filling } & $\mathrm{T}_{\text {mean }}\left({ }^{\circ} \mathrm{C}\right)$ & 23.12 & 22.89 & 17.75 & 19.28 & 22.12 & 21.9 & 16.99 & 18.45 \\
\hline & $\mathrm{T}_{\max }\left({ }^{\circ} \mathrm{C}\right)$ & 28.48 & 28.48 & 28.29 & 28.29 & 27.25 & 27.25 & 27.07 & 27.07 \\
\hline & $\mathrm{T}_{\min }\left({ }^{\circ} \mathrm{C}\right)$ & 11.19 & 1.52 & 10.5 & 10.36 & 11.3 & 15.86 & 10.26 & 10.26 \\
\hline & $\mathrm{T}_{\text {accumulated }}\left({ }^{\circ} \mathrm{C}\right)$ & 794.79 & 727.12 & 484.93 & 501.97 & 760.56 & 695.81 & 464.05 & 480.35 \\
\hline
\end{tabular}

and carbohydrate translocation from source organs to grains would eventually cause poor grain filling (Fu et al., 2019). Unlike in regular conditions, nitrogen fertilizer application could reduce the grain yield in low temperature treatment because of the reduced filling rates (Cao et al., 2018; Jia et al., 2019). Moreover, nitrogen panicle fertilizer has different effects on different cultivars (Fageria and Santos, 2015; Ding et al., 2020). Thus, the differential responses of super rice cultivars and LT in the filling stage to NPF were discovered in this study. Three experimental factors, including filling stage temperatures, NPF levels, and varieties were used in this study to clarify the mechanism of super rice varieties with different sink activities response to LT and NPF, which is critical to the accurate underlying mechanism of the effect of nitrogen fertilizer on super rice varieties with LT condition.

\section{MATERIALS AND METHODS}

\section{Experimental Sites}

The field experiments were conducted in 2016 and 2017 in the subtropical environment of Danyang City, Jiangsu Province, China $\left(32^{\circ} 0^{\prime} \mathrm{N}, 119^{\circ} 70^{\prime} \mathrm{E}, 51 \mathrm{~m}\right.$ altitude). Weeds, pests, and diseases were intensively controlled to avoid yield loss. The climate data regarding daily radiation and air temperature were measured at a meteorological station located within $1 \mathrm{~km}$ of the experimental site. The daily solar radiation and temperature were measured by a silicon pyranometer (LI-200, LI-COR Inc., Lincoln, NE, USA) and a temperature/RH probe (HMP45C, Vaisala Inc., Helsinki, Finland), respectively. The meteorological data of the two rice growing seasons were shown in Table 1.

\section{Experimental Design}

The experiments were randomized in a complete block design with three replications. Two conventional japonica varieties, namely, Nanjing 9108th (N9108) and Ningjing 7th (N7), with two grain filling temperature, namely, LT (implement by setting late sowing date, average temperature $=20.3^{\circ} \mathrm{C}$ ) and $\mathrm{CK}$ (implement by setting early sowing date, average temperature $=24.7^{\circ} \mathrm{C}$ ), were used. Two different nitrogen panicle fertilizer (NPF) levels were adopted in this study, namely, no NPF (N0), and $150 \mathrm{~kg} \mathrm{~N} \mathrm{ha}^{-1}$ at panicle initiation (N150), and were applied in panicle initiation. The whole experimental field was applied with the same amount of $450 \mathrm{~kg} \mathrm{P} \mathrm{ha}{ }^{-1}$ (Calcium superphosphate) $+150 \mathrm{~kg} \mathrm{~K} \mathrm{ha}^{-1}$ at transplanting, and $150 \mathrm{~kg}$ $\mathrm{K} \mathrm{ha}-{ }^{1}$ at panicle initiation stage (Potassium chloride) $+330 \mathrm{~kg}$ $\mathrm{N} \mathrm{ha}^{-1}$ as carbamide at transplanting in 2016 and 2017. The soil properties of the topsoil layer $(0-20 \mathrm{~cm})$ before transplanting were measured in both years as follows: $1 \mathrm{~kg}$ soil contains $1.25 \mathrm{~g}$ total $\mathrm{N}, 6.8 \mathrm{mg} \mathrm{NH}_{4}^{+}, 0.9 \mathrm{mg} \mathrm{NO}-27.9 \mathrm{mg}$ Olsens-P and $168 \mathrm{mg}$ $\mathrm{NH}_{4} \mathrm{OAc}-\mathrm{K}$, and $\mathrm{pH}=6.3$. Seedlings were sowed on May 30 and July 1, and machine-transplanted on June 20 (CK) and July 20 (LT) in 2016 and 2017, respectively, with the hill spacing for $14 \mathrm{~cm} \times 30 \mathrm{~cm}$. Machine-transplantation was performed using a rice trans-planter (PZ640, Iseki Agricultural Machinery Co., Ltd., Japan).

\section{Observations and Measurements Development Stage}

The dates of sowing, panicle initiation, heading, and maturity were recorded for determining growth duration. Panicle initiation was defined as the day when $80 \%$ of stems in a plot 
presented a white feathery cone inside the leaf sheath of the rice plant. Heading was the date when $80 \%$ of the stems in a plot started anthesis. Maturity was the date when $95 \%$ of grains turned yellow.

\section{Yield and Yield Components}

At panicle initiation, heading, and maturity stages, all the plants within an area of $0.5 \mathrm{~m}^{2}$ in each plot were sampled for the growth analysis. After recording the plant height, the numbers of stems (main stems plus tillers), and panicles (when presented), the plant samples were separated into leaves, stems, and panicles. At maturity, the panicles were hand-threshed, and the filled spikelets were separated from the unfilled spikelets by submerging them into tap water. The empty spikelets were separated from the half-filled spikelet by winnowing. Three sub-samples of the filled $(30 \mathrm{~g})$, the half-filled $(6 \mathrm{~g})$, and the empty $(3 \mathrm{~g})$ spikelets were taken to count the spikelets number. The dry weights of the rachis, filled, half-filled, and empty spikelets were measured after oven drying at $70^{\circ} \mathrm{C}$ to a constant weight. The total dry weight at maturity was the sum of the dry weights of the straw (leaves plus stems), rachis, and filled, half-filled and empty spikelets. The spikelets per panicle (spikelets $\mathrm{m}^{-2}$ /panicles $\mathrm{m}^{-2}$ ), and grain filling percentage $\left(100 \times\right.$ filled spikelets $\mathrm{m}^{-2} /$ spikelets $\left.\mathrm{m}^{-2}\right)$ were calculated. The grain yield was determined from a $5 \mathrm{~m}^{2}$ area in the center of each plot and was adjusted to $14 \%$ moisture content.

\section{Grain Filling Characteristics}

We selected 400 panicles that headed on the same day in each treatment, which were tagged to give an accurate record of the flowering date and the position of the spikelets. Superior grains (located on apical primary branches, SS) that flowered on the first 2 days of anthesis (DAA) and inferior grains (located on proximal secondary branches, IS) that flowered on the last 2 days were separated from the panicles (Chen et al., 2013). Thirty tagged panicles from each plot were sampled at every 5 DAA till 45 DAA. The sampled panicles were divided into three groups (10 panicles each) as three replicates. Then, superior and inferior spikelets were separated from the panicles for RNA extraction and measurement of soluble sugars and starch. All the sampled grains were deshelled and immersed in liquid nitrogen and then kept in a $-80^{\circ} \mathrm{C}$ freezer for further analysis. Further 30 tagged panicles (10 panicles formed a subsample) from each treatment were sampled to measure the dry weight of superior and inferior grains at final harvest. The sampled grains were dried at $70^{\circ} \mathrm{C}$ to constant weight, dehulled, and weighed.

\section{RNA Extraction and qRT-PCR}

Total RNA was extracted from $0.1 \mathrm{~g}$ of inferior seeds (IS) and superior seeds (SS) of rice plants at 5, 10, 15, and $20 \mathrm{DAA}$ using RNeasy Plant Mini Kit (Qiagen, German) following the method described previously (Wang et al., 2017). First-strand cDNA was synthesized from RNA using the RNAprep Pure (Tiangen, Beijing, China). Relative expression levels of target genes, such as FLO4, SBE1, and PHO-l, were detected by the Real-time PCR System (Takara, Dalian, China). Primers were designed based on the anticipated size of the amplification products (150-250 bp) as listed in Supplementary Table 1.
Primer Premier 5.0 software (Premier, Ottawa, ON, Canada) was used to complete the design work. Three biological replicates were used. Expression levels were normalized to the reference genes: Actin (OSNPB_110163100). The primers were designed as shown in Supplementary Table 1.

\section{Assays of Grain Weight, Non-structural Soluble Carbohydrates, and Starch Content}

To investigate how sowing date affected the grain-filling process, we measured the weight of superior and inferior grains, and the contents of soluble sugars and starch of the inferior grains under the two water supply treatments. A total of 100 SS and IS grains each was used for the measurement of grain dry weight. The samples used for measuring the starch and non-structural soluble carbohydrate (NSC) contents were ground into fine powder, and $500 \mathrm{mg}$ ethanol (v/v) was added. The tubes were kept in a water bath at $80^{\circ} \mathrm{C}$ for $30 \mathrm{~min}$. After cooling the tubes in water, they were centrifuged at $5,000 \times \mathrm{g}$ for $10 \mathrm{~min}$. The supernatant was collected, and the extraction was repeated three times. The sugar extract was then diluted to $50 \mathrm{ml}$ with distilled water and the sucrose content was measured as described by Yang et al. (2001a,c). The residues left in the centrifuge tubes after extracting sugars were dried at $80^{\circ} \mathrm{C}$ for starch extraction using $\mathrm{HClO}_{4}$ following the method described by Yang et al. (2001c). Amylose and amylopectin contents were determined according to $\mathrm{He}$ (1985) with minor changes. Amylose content was quantified at 620 and $479 \mathrm{~nm}$, while amylopectin content was quantified at 556 and $737 \mathrm{~nm}$, respectively.

\section{Metabolite Extraction and Quantification}

Fifty milligrams of plant sample was weighed into a $2 \mathrm{ml}$ plastic microtube and frozen in liquid nitrogen, dissolved in $1 \mathrm{ml}$ methanol/water/formic acid solution (15:4:1, v/v/v). Ten microliters of internal standard mixed solution $(100 \mathrm{ng} / \mathrm{ml})$ was added into the extract as internal standards for the quantification. The mixture was vortexed for $10 \mathrm{~min}$, and centrifuged for $5 \mathrm{~min}\left(12,000 \mathrm{rpm} / \mathrm{min}\right.$, and $\left.4^{\circ} \mathrm{C}\right)$, and the supernatant was then transferred to clean plastic microtubes, followed by evaporation to dryness and dissolved in 100 $\mu \mathrm{l} 80 \%$ methanol $(\mathrm{v} / \mathrm{v})$, and filtered through a $0.22 \mu \mathrm{m}$ membrane filter for further LC-MS/MS analysis. ABA and ACC contents were detected by MetWare (http://www.metware.cn/) based on the AB Sciex QTRAP 6500 LC-MS/MS platform (Wuhan Metware Biotechnology Co., Ltd., Wuhan, China). The quantification of ACC and ABA were analyzed using an UPLCESI-MS/MS system (UPLC'ExionLC ${ }^{\mathrm{TM}}$ AD' https://sciex.com. cn/; MS’Applied Biosystems 6500 Triple Quadrupole, https:// sciex.com.cn/). The content of ACC and ABA was determined using the external standard method and is expressed as $\mathrm{ng} / \mathrm{g}$ fresh weight (FW). Three biological replications were performed.

\section{Statistics Analyses}

Analysis of variance was performed using SPSS version 20.0 (SPSS Statistics, SPSS Inc., Chicago, USA), and the results are expressed as means $( \pm S D)$ of three biological replicates. The treatment means were compared based on the least significant difference (LSD) at a 0.05 level of probability. 
TABLE 2 | Growth duration (dates and days after sowing) of each growth stage in response to CK and LT treatments of two varieties (N7 and N9108) of 2016 and 2017.

\begin{tabular}{llcccccc}
\hline Varieties & Treatments & Sowing & Transplanting & Panicle initiation & Heading & Grain weight stable & Mature \\
\hline N9108 & CK & $(5.31) 0$ & $(6.20) 21$ & $(7.27) 58$ & $(8.26) 88$ & $(9.30) 123$ & $(10.30) 153$ \\
& LT & $(7.10) 0$ & $(7.20) 20$ & $(8.16) 47$ & $(9.17) 79$ & $(10.27) 119$ \\
N7 & CK & $(5.31) 0$ & $(6.20) 21$ & $(7.29) 60$ & $(8.30) 92$ & $(10.4) 127$ \\
& LT & $(7.1) 0$ & $(7.20) 20$ & $(8.15) 46$ & $(9.16) 78$ & $(10) 21)(13)$ \\
\hline
\end{tabular}

TABLE 3 | Yield components of rice varieties (N7 and N9108) in response to fertilizer treatments (N0 and N150) and different filling stage temperatures (CK and LT) in 2016 and 2017.

\begin{tabular}{|c|c|c|c|c|c|c|}
\hline \multirow[t]{2}{*}{ Year } & \multirow[t]{2}{*}{ Varieties } & \multirow[t]{2}{*}{ Treatments } & \multirow{2}{*}{$\frac{\text { Total spikelets number }}{\left(\mathbf{m}^{-2}\right)}$} & \multirow{2}{*}{$\begin{array}{c}\text { Seed-setting rate } \\
(\%)\end{array}$} & \multirow{2}{*}{$\begin{array}{c}1,000 \text {-grain weight } \\
\text { (g) }\end{array}$} & \multirow{2}{*}{$\begin{array}{c}\text { Grain yield } \\
\text { (t/ha) }\end{array}$} \\
\hline & & & & & & \\
\hline \multirow[t]{8}{*}{2017} & N9108 & N150-CK & $48796.8 b$ & 85.2ab & $30.37 a$ & $12.06 a$ \\
\hline & & NO-CK & $34233.3 c$ & $89.4 a$ & $30.50 a$ & $9.33 c$ \\
\hline & & N150-LT & $53080.3 a$ & $76.7 \mathrm{c}$ & $28.41 b$ & $11.42 b$ \\
\hline & & NO-LT & $47486.3 b$ & $80.8 b$ & 29.11ab & $10.17 b$ \\
\hline & N7 & N150-CK & $51236.7 a$ & 75.6ab & 27.67ab & $10.87 a$ \\
\hline & & NO-CK & 40887.7b & $82.1 \mathrm{a}$ & $28.22 \mathrm{a}$ & $9.47 b$ \\
\hline & & N150-LT & $55838.3 a$ & $60.1 d$ & 27.91ab & $9.36 b$ \\
\hline & & NO-LT & $52644.0 a$ & $66.8 \mathrm{c}$ & $26.98 b$ & $9.20 \mathrm{~b}$ \\
\hline \multirow[t]{8}{*}{2016} & N9108 & N150-CK & $45512.3 a$ & $84.1 \mathrm{ab}$ & $28.86 a$ & $11.91 a$ \\
\hline & & NO-CK & $27558.7 b$ & $90.1 \mathrm{a}$ & $28.88 \mathrm{a}$ & $9.23 b$ \\
\hline & & N150-LT & 41615.3a & $75.1 b$ & 27.67ab & $9.33 b$ \\
\hline & & NO-LT & $44336.5 a$ & $82.1 \mathrm{ab}$ & $26.09 b$ & $10.23 a b$ \\
\hline & $\mathrm{N} 7$ & N150-CK & $55499.0 a$ & $78.7 b$ & $26.71 \mathrm{a}$ & $10.93 a$ \\
\hline & & NO-CK & 40963.6b & $85.6 a$ & $25.89 b$ & $9.08 b$ \\
\hline & & N150-LT & $53182.0 \mathrm{a}$ & $65.6 c$ & $26.36 a$ & $9.20 \mathrm{~b}$ \\
\hline & & NO-LT & $46760.4 \mathrm{ab}$ & $77.3 b$ & $26.12 \mathrm{ab}$ & $9.45 b$ \\
\hline
\end{tabular}

Letters after the values indicate statistical significance at the $P=0.05$ level.

\section{RESULTS}

\section{Grain Yield and Yield Components}

The present study was carried out to determine the effect of different temperature and sowing dates on the yield and yield related attributes of rice during the rice-growing seasons 201718 as presented in Table 1. To accomplish the filling stage temperature treatments in the field, two different sowing date treatments were adopted. Lower Mean temperature (Tmean), Day temperature (Tday), and Night temperature (Tnight) and shorter growth duration were found in LT treatment compared to that in CK treatment (Tables 1, 2). The LT and NPF treatments showed a significant effect on total spikelets number, seed setting rate, and 1,000-seed weight that determine the yield of the rice. The total spikelet number could be enhanced by both NPF and LT treatments while seed setting rate and 1,000-seed weight reduced. Moreover, their balancing eventually altered the grain yield (Table 3). However, the grain yield responds differentially to NPF between CK and LT treatments. Under CK condition, the grain yields of N9108 and N7 could be significantly improved by NPF for about 12.7 and 9.4\%, respectively, mainly due to enhanced population size (total spikelet number). However, under LT conditions, the grain yield of both varieties showed no significant change if NPF was applied or not since significantly lower seed-setting rate and 1,000-seed weight were observed, although their total spikelet number increased at the same time. The higher seed-setting rate $(12.3 \pm 2.4 \%)$ and 1,000 -seed weight $(7.4 \pm 1.3 \%)$ of both varieties were found in CK treatment compared to those in LT treatment. Similarly, a lower seedsetting rate $(9.1 \pm 1.7 \%)$ of both varieties could be induced by applying NPF.

\section{Grain Filling Rate}

As shown in Table 4, the grain filling rate of N9108 is significantly higher than that of N7, and it is more significant under the LT condition (Figure 1). Under CK condition, the inferior and superior mean grain filling rate $\left(\mathrm{GR}_{\text {mean }}\right)$ of $\mathrm{N} 9108$ were 0.504 \pm 0.073 and $0.811 \pm 0.053\left(\mathrm{mg} \cdot\right.$ grain $\left.^{-1} \cdot \mathrm{D}^{-1}\right)$, respectively, was about 25 and $43 \%$ higher than those of N7 [0.372 \pm 0.079 and $0.617 \pm 0.033\left(\mathrm{mg} \cdot\right.$ grain $\left.\left.^{-1} \cdot \mathrm{D}^{-1}\right)\right]$. However, under LT condition, the $\mathrm{GR}_{\text {mean }}$ of inferior and superior grains in N9108 were about $0.416 \pm 0.075$ and $0.803 \pm 0.03\left(\mathrm{mg} \cdot\right.$ grain $\left.^{-1} \cdot \mathrm{D}^{-1}\right)$, which were significantly higher than those of $\mathrm{N} 7[0.324 \pm 0.069$ and $0.595 \pm 0.011\left(\mathrm{mg} \cdot\right.$ grain $\left.^{-1} \cdot \mathrm{D}^{-1}\right)$ ], with an increment of about 40 and $67 \%$ compared with those of CK condition. In this study, both NPF and LT treatments reduced the grain filling rate of the two varieties, delayed the time to reach the maximum grain filling rate, and increased the initial grain filling potential (Table 4). When NPF was applied, the inferior grain 
TABLE 4 | Grain filling characteristics of different grain positions (SS and IS) of rice varieties (N7 and N9108) in different fertilizer treatments (N150, applying NPF treatment; NO, no NPF treatment) and temperature treatments (CK and LT).

\begin{tabular}{|c|c|c|c|c|c|c|c|}
\hline Materials & $\begin{array}{l}\text { Treatment and } \\
\text { position }\end{array}$ & $\mathbf{R}_{0}$ & $\begin{array}{c}\text { GR }_{\max } \\
\left(\mathrm{mg} \cdot \mathrm{grain}^{-1} \cdot \mathrm{D}^{-1}\right)\end{array}$ & $\begin{array}{l}T_{\max } \\
\text { (d) }\end{array}$ & $\begin{array}{c}W_{\max } \\
\left(\mathrm{mg} \cdot \mathrm{grain}^{-1}\right)\end{array}$ & $\begin{array}{c}\text { GR }_{\text {mean }} \\
\left(\mathrm{mg} \cdot \text { grain }^{-1} \cdot \mathrm{D}^{-1}\right)\end{array}$ & $\begin{array}{l}\text { D } \\
\text { (d) }\end{array}$ \\
\hline \multirow[t]{8}{*}{ N9108 } & N150-CK-SS & $0.70 \mathrm{a}$ & $1.5 a b$ & $11.58 \mathrm{c}$ & $28.48 \mathrm{a}$ & $0.74 a b$ & $38.94 \mathrm{bc}$ \\
\hline & NO-CK-SS & $0.15 d$ & $1.71 \mathrm{a}$ & $15.04 b$ & $28.13 a$ & $0.85 a$ & $33.08 c$ \\
\hline & N150-LT-SS & $0.43 b$ & $1.58 \mathrm{a}$ & $9.64 d$ & $25.49 b$ & $0.78 a b$ & $32.64 c$ \\
\hline & NO-LT-SS & $0.31 c$ & $1.60 \mathrm{a}$ & $11.98 \mathrm{c}$ & $26.53 b$ & $0.80 a$ & $32.05 c$ \\
\hline & N150-CK-IS & $0.20 \mathrm{~cd}$ & $0.72 \mathrm{c}$ & $22.27 a$ & $22.57 \mathrm{c}$ & $0.36 c$ & $56.51 a$ \\
\hline & NO-CK-IS & $0.09 e$ & $1.21 \mathrm{~b}$ & $21.66 a$ & $24.27 \mathrm{bc}$ & $0.60 \mathrm{~b}$ & 40.46 \\
\hline & N150-LT-IS & $0.31 c$ & $0.67 c$ & 13.73bc & $17.41 d$ & $0.34 c$ & $56.3 a$ \\
\hline & NO-LT-IS & $0.29 c$ & $0.86 c$ & $14.05 b c$ & $19.17 \mathrm{~cd}$ & $0.43 \mathrm{bc}$ & $46.68 b$ \\
\hline \multirow[t]{8}{*}{ N7 } & N150-CK-SS & $0.11 a b$ & $1.17 \mathrm{~b}$ & $16.18 \mathrm{c}$ & $24.74 a$ & $0.58 b$ & $42.63 b$ \\
\hline & NO-CK-SS & $0.07 b$ & $1.51 a$ & $22.72 a$ & $23.96 a$ & $0.75 a$ & $31.66 c$ \\
\hline & N150-LT-SS & $0.19 a$ & $1.11 \mathrm{~b}$ & $13.45 d$ & $22.48 a b$ & $0.56 b$ & 43.08b \\
\hline & NO-LT-SS & $0.19 a$ & $1.09 b$ & $14.57 \mathrm{~cd}$ & $21.12 b$ & $0.50 \mathrm{bc}$ & $39.28 \mathrm{bc}$ \\
\hline & N150-CK-IS & $0.11 a b$ & $0.59 d$ & 20.58ab & $15.12 \mathrm{bc}$ & $0.29 d$ & $65.21 a$ \\
\hline & NO-CK-IS & $0.08 b$ & $0.87 \mathrm{bc}$ & $22.27 a$ & $19.88 b$ & $0.44 c$ & 46.31b \\
\hline & N150-LT-IS & $0.09 b$ & $0.77 \mathrm{c}$ & 18.83b & $13.08 \mathrm{c}$ & $0.39 c$ & 41.86b \\
\hline & NO-LT-IS & $0.07 b$ & $0.83 \mathrm{bc}$ & $19.22 b$ & $15.03 \mathrm{bc}$ & $0.41 c$ & $38.29 b c$ \\
\hline
\end{tabular}

$R_{0}$, Initial grain filling potential; GRmax, Maximum grain filling rate; $T_{\text {max. }}$ Time reaching the maximum grain filling rate; $W_{\text {max }}, W e i g h t$ of a kernel at the time of maximum grain filling rate; GR mean, Mean grain filling rate; $D$, The time of grain filling reaching $99 \%$.

Letters after the value indicate statistical significance at the $P=0.05$ level.

filling rate of N9108 and N7 decreased by about $16 \pm 2.7 \%$ and $27 \pm 8.3 \%$, respectively. The time to reach the maximum filling rate was delayed by about $13 \pm 3.3 \%$ and $21 \pm 7.1 \%$, and the initial grain filling potential decreased by about $13 \pm 5.4 \%$ and $15 \pm 7.8 \%$. In addition, the covariance $(\mathrm{CV})$ of filling rates significantly differed by varieties and seed positions, indicating their differential stability. The $\mathrm{CV}$ of $\mathrm{GR}_{\text {mean }}$, max grain filling rate $\left(\mathrm{GR}_{\max }\right)$, and max grain weight $\left(\mathrm{W}_{\max }\right)$ in inferior seeds of $\mathrm{N} 7$ were $0.33,0.21$, and 0.31 , respectively. The $\mathrm{CV}$ of $\mathrm{GR}_{\text {mean }}$, $\mathrm{GR}_{\max }$, and $\mathrm{W}_{\max }$ in superior seeds of $\mathrm{N} 7$ were $0.12,0.09$, and 0.13 , respectively. Differently, the $\mathrm{CV}$ of $\mathrm{GR}_{\operatorname{mean}}, \mathrm{GR}_{\max }$, and $\mathrm{W}_{\max }$ in inferior seeds of $\mathrm{N} 9108$ were $0.22,0.14$, and 0.21 , respectively. The $\mathrm{CV}$ of $\mathrm{GR}_{\text {mean }}, \mathrm{GR}_{\max }$, and $\mathrm{W}_{\max }$ in superior seeds of $\mathrm{N} 9108$ were $0.07,0.04$, and 0.04 , respectively. It is obvious that the stability of superior and inferior grain filling levels of N9108 was significantly higher than those of N7. The stability of the superior grain filling level of both varieties was higher than that of inferior grain filling, which indicated that grain filling of inferior seeds could be more regulated by NPF and LT treatments.

\section{Starch Accumulation}

The starch accumulation pattern was consistent with the grain filling rates results as shown in Figure 2. In Figure 2, the starch accumulation of both inferior and superior seeds in N9018 is significantly higher than that in N7. Compared to superior seeds, the starch accumulation and filling rates were significantly higher than that of inferior seeds (Figures 1, 2). Unlike inferior seeds, the starch accumulation of superior seeds was not significantly regulated by temperature and fertilizer treatments. Under CK conditions, the total amount of starch accumulation in inferior seeds was suppressed by NPF. The LT treatment showed a lower inferior seeds starch accumulation compared to that of CK, and the application of NPF had no significant effect under LT conditions. The suppression effect of NPF on starch accumulation in CK condition was higher than that in the LT condition, which was consistent with grain filling results (Figure 2). On the other hand, the effect of temperature and fertilizer treatment on the starch accumulation of N7 was significantly higher than those of N9108 (Figure 2).

To further provide metabolism level clues about changing the biosynthesis of starch, we measured the key intermediate metabolite, amylose, and amylopectin content. We found that, similar to the changing pattern of total starch accumulation, the amylose and amylopectin contents of both varieties were increased rapidly in all measured periods (Figure 5). The content of amylose and amylopectin was significantly reduced by LT and NPF treatments in both varieties. On the other hand, the dynamics of amylose and amylopectin were lower in N7 compared to that in N9108, which is consistent with gene expression data (Figure 3).

\section{Gene Expression}

Since the grain filling difference of superior seeds in both varieties among different treatments was not significant, it could be concluded that the difference of grain weight was mainly derived from inferior seeds starch biosynthesis among all treatments. Thus, the relative expression levels of genes related to starch accumulation in inferior seeds were verified in this study (Figure 3). Due to starch, synthesis could be controlled 

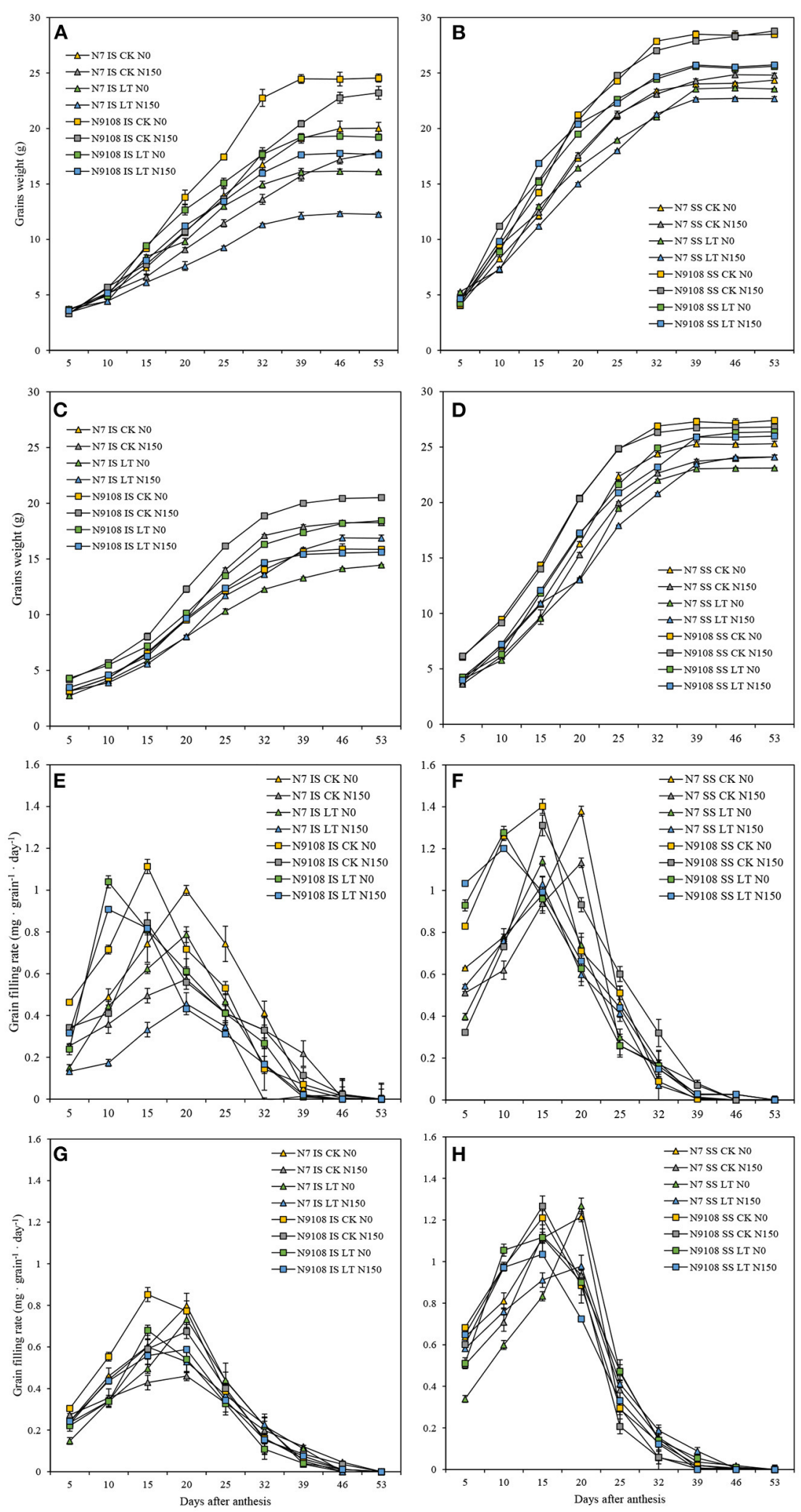

FIGURE 1 | Grain weight and filling rate dynamics of superior (SS) and inferior (IS) in two varieties [Nanjing 7th (N7) and Nanjing 9108th (N9108)] in response to different fertilizer treatments [N150, Applying nitrogen panicle fertilizer (NPF) treatment; NO, No NPF treatment] in filling stage temperature treatments [Normal 
FIGURE 1 | temperature (CK) and Low temperature (LT) of 2016 and 2017]. (A) Grain weight dynamics of IS in 2016; (B) Grain weight dynamics of SS in 2016; (C) Grain weight dynamics of IS in 2017; (D) Grain weight dynamics of SS in 2017. (E) Grain filling rate dynamics of IS in 2016; (F) Grain filling rate dynamics of SS in 2016; (G) Grain filling rate dynamics of IS in 2017; (H) Grain filling rate dynamics of SS in 2017.
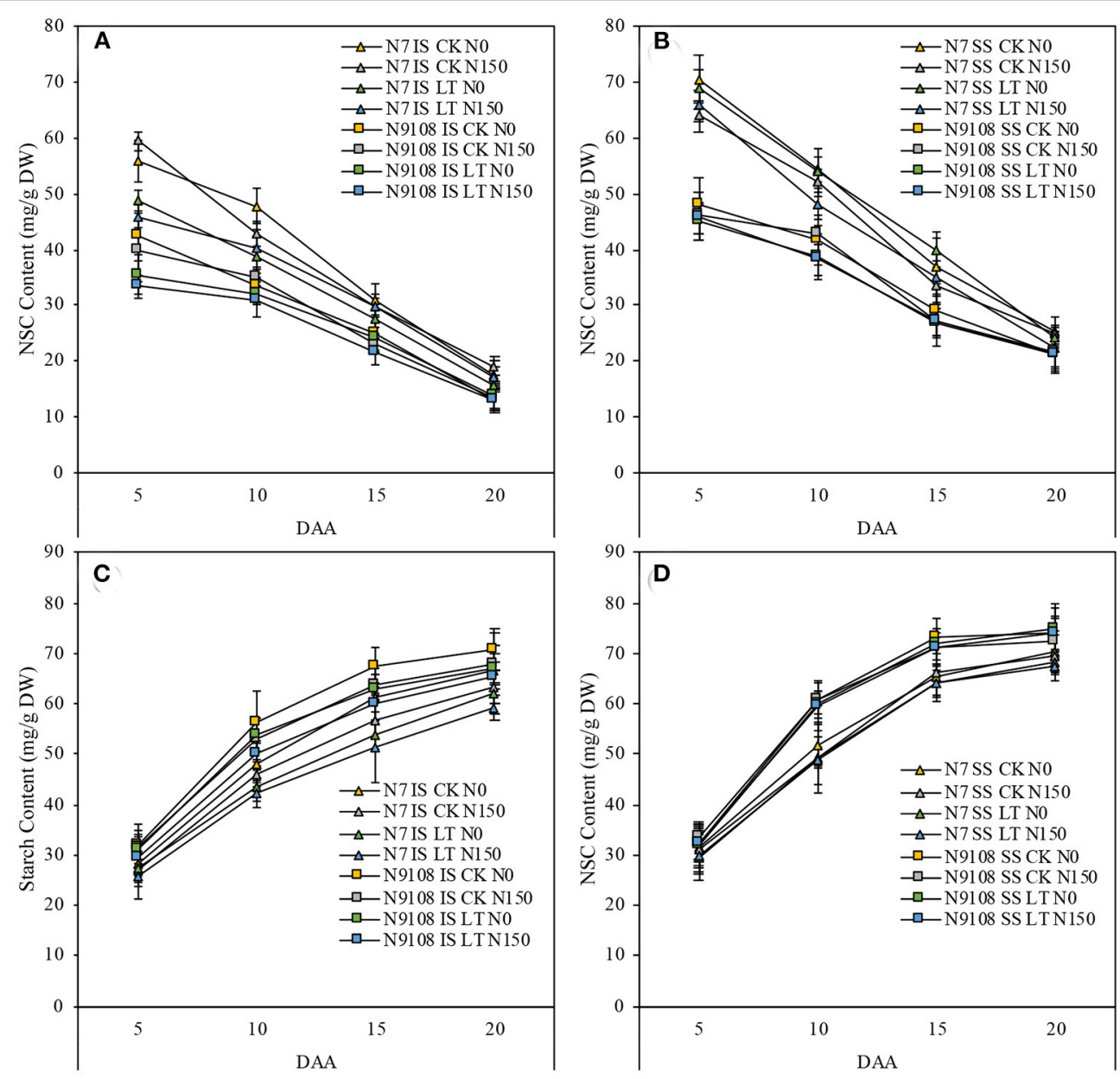

FIGURE 2 | Effect of different nitrogen panicle fertilizer levels (N150: Applying NPF treatment; NO, No NPF treatment) on starch and non-structural soluble carbohydrate (NSC) accumulation dynamics under different filling stage temperature treatments (CK and LT) in IS and SS. DW, dry weight. Values are means ( \pm SD) of three replicates. Samples were taken at 5 days after anthesis (DAA), 10 DAA, 15 DAA, and 20 DAA. (A) NSC dynamics of IS in N7 and N9108, respectively; (B) NSC dynamics of SS in N7 and N9108, respectively; (C) Starch dynamics of IS in N7 and N9108, respectively; (D) Starch dynamics of SS in N7 and N9108.

by several key enzymes including starch synthase (SSS, encoded by FLO4), starch branching enzyme (SBE, encoded by SBE I), and starch phosphorylase (SPS, encoded by PHO-l) (Yoshida and Hara, 1977; Yang et al., 2001a; Zhao et al., 2004; Zhu et al., 2004; Duan and Sun, 2005). The expression pattern of the above genes was measured by qRT-PCR and was consistent with the physiological results (Figure 2). FLO4 gene expression was high and kept stable from 5 DAA (Figure 3). FLO4 expression, in both varieties under CK condition, was higher than those under LT condition, but there was no significant difference among different NPF application treatments. The expression of SBE1 in superior and inferior grains increased continuously, while the expression of $P H O-l$ in superior and inferior grains increased continuously from 0 to $15 \mathrm{DAA}$ and then decreased slightly since $15 \mathrm{DAA}$. The expression of SBE1 and PHO-l were significantly suppressed by LT and NPF treatments. Overall, the expression levels of N9108 were significantly higher than those in N7, which indicated a higher starch biosynthesis ability (Figure 3). The gene expression data was consistent with the enzymatic activities data in Figure 4. The encoded gene expression levels and activities of SBE, SPS, and $S S$ were significantly suppressed by LT and NPF treatments, which also indicated suppressed starch biosynthesis ability.

\section{Contents of Hormones Related to Grain Filling}

In this study, we measured the content of $\mathrm{ABA}$ and $\mathrm{ACC}$ of inferior seeds among different treatments at three grainfilling stages. The ABA concentration was low at the early 


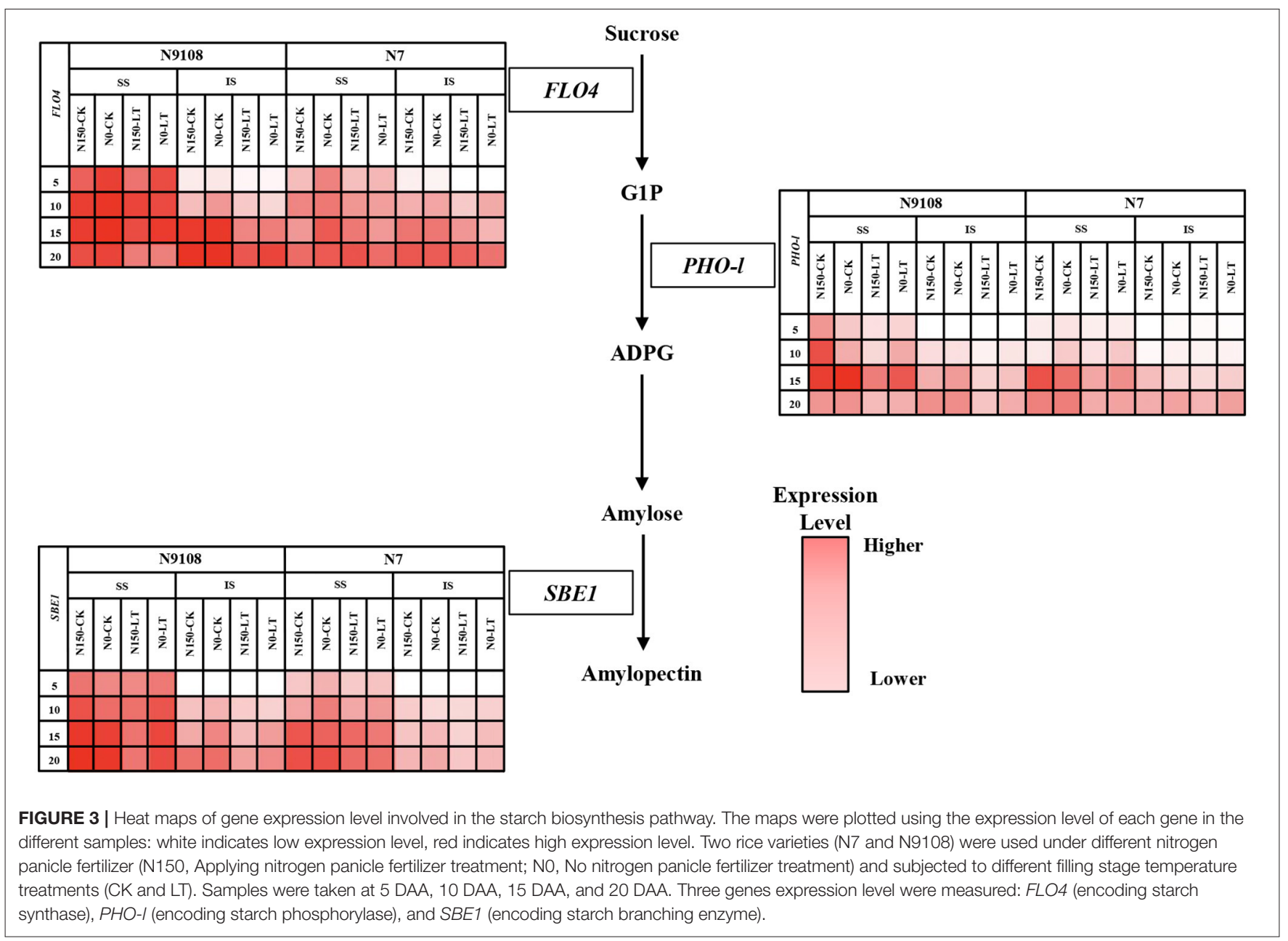

grain filling stage, increased from 10 DAA, reached a peak at $15 \mathrm{DAA}$, and declined at $20 \mathrm{DAA}$. In all treatments, the concentration of ABA was significantly decreased by LT and NPF treatments compared to CK and no NPF treatments, respectively (Figure 5). The reduction was more severe in additive LT and NPF treatment compared to other treatments. In contrast to $\mathrm{ABA}$, the concentration of ACC was high at the early grain filling stage (Figure 6) but continuously declined until 20 DAA. Throughout the grain filling period, the concentration of ACC was largely enhanced by LT and NPF treatments compared to CK and no NPF treatments, respectively. Similar to ABA changing pattern, we found a large increment of ACC concentration in additive LT and NPF treatment compared to other treatments. The variance of ACC responding to NPF was more pronounced than that of LT. The ABA concentration of N9108 among all duration was significantly higher than that of N7, while ACC concentration showed no significant difference.

\section{DISCUSSION}

\section{NPF and LT Affects Grain Yield}

Nitrogen is one of the most important elements for plant growth, and the application of nitrogen fertilizers plays an important role in increasing rice yield due to their increment on total spikelet number (Fu et al., 2019; Wang et al., 2019). However, previous studies also proved that inappropriate nitrogen panicle fertilizer could reduce the grain filling of rice in the field (Ohnishi et al., 1999; Yang A. et al., 2004; Singh et al., 2011; Jiang et al., 2016; Zhang et al., 2021). The grain yield of both varieties could be enhanced by applying NPF since their larger population size. NPF increased grain yield for $11.7 \pm 3.3 \%$ and $1.6 \pm 0.9 \%$ under CK and LT conditions, respectively. This meant that the effect of NPF on grain yield was not significant under LT condition (Table 3). Under LT condition, the NPF induced enhancement of the population size and could exaggerate the filling issue similar to how a previous study (Fu et al., 2019) reported. This study explained that under abiotic stress in the filling stage, the grain yield of high nitrogen level was even lower than that of low nitrogen level due to insufficient grain filling. Unlike the responding pattern of the grain yield, both NPF and LT suppressed the grain filling while NPF enhanced grain yield as in previous studies since the increment on total spikelet number (Ding et al., 2003; Wang et al., 2015; Peng, 2016; Fu et al., 2019). Since $20 \pm 4.9 \%$ higher total spikelet number and $9.7 \pm 2.1 \%$ lower grain yield was found in N7 compared to those in N9108, it could be concluded that the major difference of the grain 

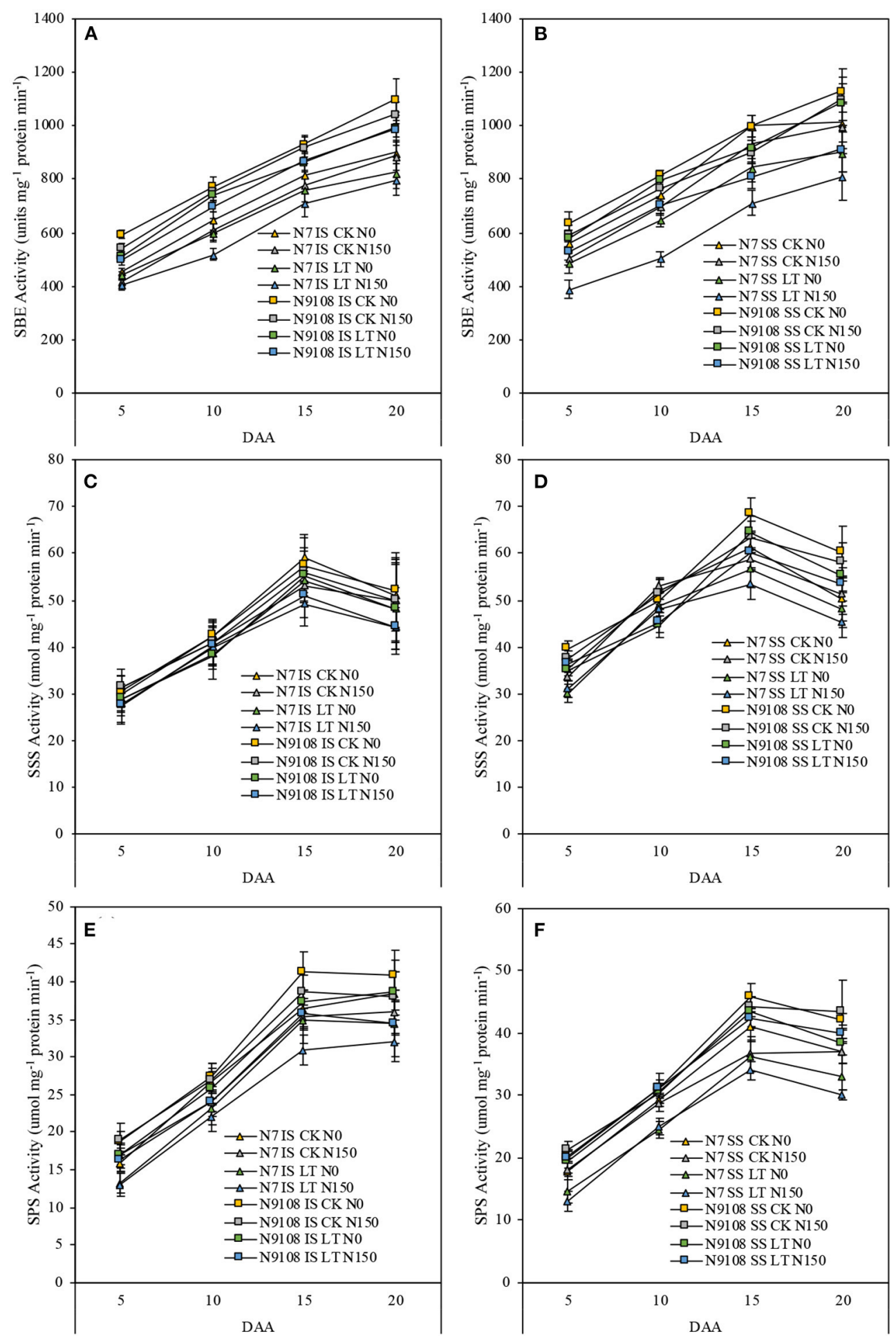

FIGURE 4 | Starch-biosynthesis related enzymes activities (starch branching enzymes (SBE): encoded by SBE1, starch synthase (SSS): encoded by FLO4 and starch phosphorylase (SPS): encoded by PHO-I) in IS and SS of two rice varieties (N7 and N9108) under different nitrogen panicle fertilizer (N150, Applying NPF treatment; NO, No NPF treatment) and filling stage temperature treatments (CK and LT). Samples were taken at 5 DAA, 10 DAA, 15 DAA, and 20 DAA Values are means ( \pm SD) of three replicates. (A) SBE activities of IS in N7 and N9108, respectively; (B) SBE activities of SS in N7 and N9108, respectively; (C) SSS activities of IS in N7 and N9108, respectively; (D) SSS activities of SS in N7 and N9108, respectively; (E) SPS activities of IS in N7 and N9108, respectively; (F) SPS activities of SS in N7 and N9108, respectively. 

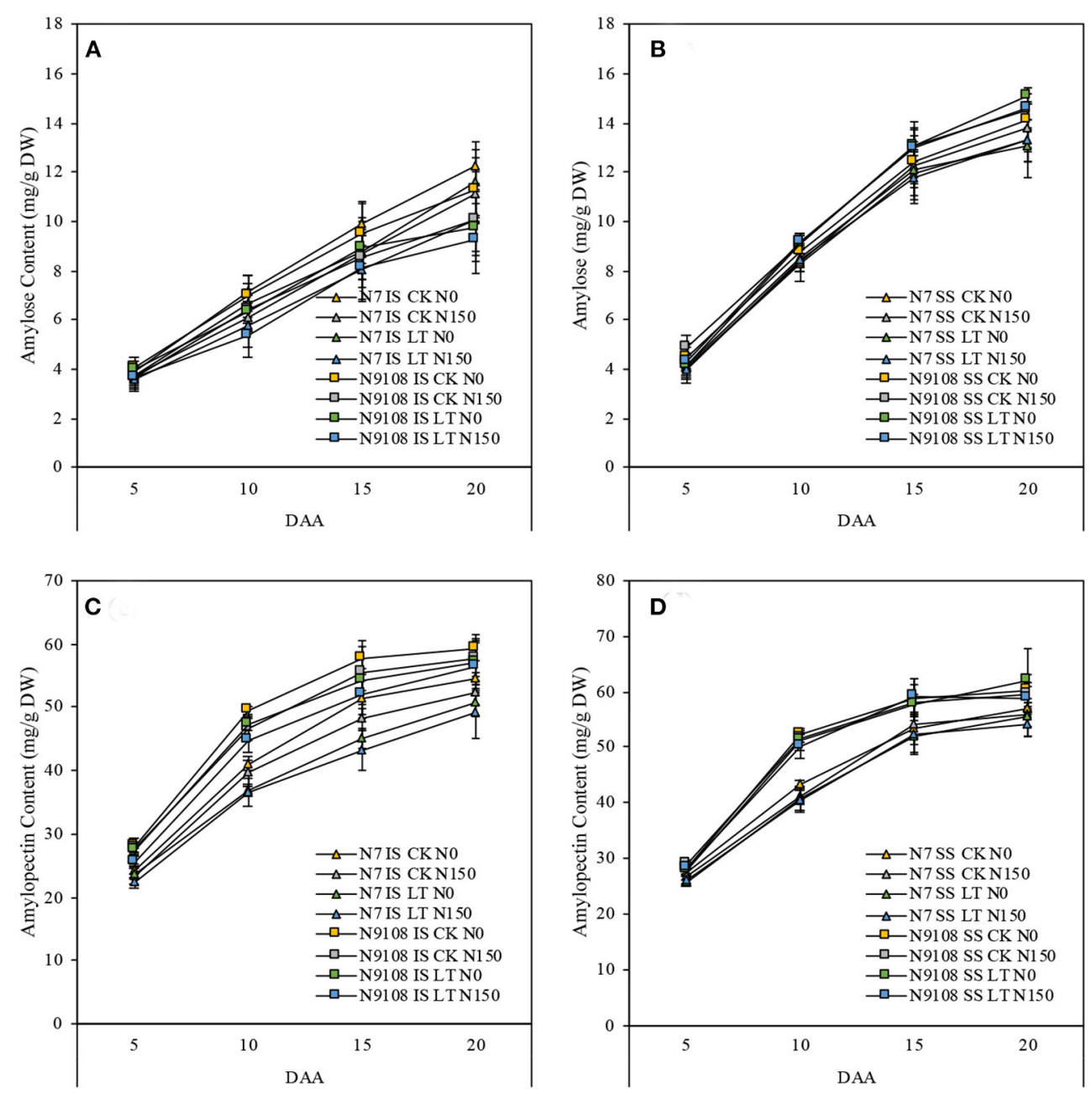

FIGURE 5 | Amylose and amylopectin accumulation dynamics from 5 DAA to 20 DAA in IS and SS of two varieties (N7 and N9108) in response to different fertilizer treatments (N150, Applying nitrogen panicle fertilizer treatment; N0, Without nitrogen panicle fertilizer treatment) and filling stage temperature treatments (CK and LT). Values are means $( \pm S D)$ of three replicates. (A) Amylose content dynamics of IS in N7 and N9108, respectively; (B) Amylose content dynamics of SS in N7 and N9108, respectively; (C) Amylopectin content dynamics of IS in N7 and N9108, respectively; (D) Amylopectin content dynamics of SS in N7 and N9108, respectively.

yield of the two varieties was mainly derived from the grain weight which was closely related to their filling level instead of their population size. The variance of grain weight of N9108 was significantly lower than that of N7 indicated their higher filling stability (Table 3). To further investigate the underlying mechanism of the different sensitivities of grain weight, the filling rate was examined in this study, and the results were consistent with the grain yield (Table 4).

Abiotic stress, like temperature, suppressed the grain filling rate by slowing enzymes activities, which further reduce the starch biosynthesis (Wang et al., 2021). In the present study, grain filling rate was suppressed by LT but, on the other hand, the late sowing of rice increases the spikelet numbers that are in line with the previous study, which in turn enhances the vegetative stage temperature and rice population size (Wang et al., 2021). As shown in the result, both NPF and LT suppressed the grain filling rate while they both enhanced the spikelet number (Table 3). It could be concluded that increasing grain filling could be a more effective method to increase grain yield in the field rather than increasing population size, since the rice population size has been already enlarged a lot due to the popularization of "super rice" varieties. The grain yield was determined by the balancing between grain filling reduction and spikelet number enhancement. Therefore, the variety selection of late sowing conditions in the middle and lower reaches of the Yangtze River could be guided by strong sink activity rather than sink capacity. The varieties with higher sink activities showed higher LT and NPF adaptivity than low sink activities varieties in this study. The reduction of grain filling level in response to NPF and LT was further proved by lower sugarto-starch conversion and starch biosynthesis level. Low starch content was found to be produced under LT and NPF conditions, mainly due to lower expression levels of starch biosynthesis correlated with gene expression (FLO4, PHO-l, and SBE1). A 

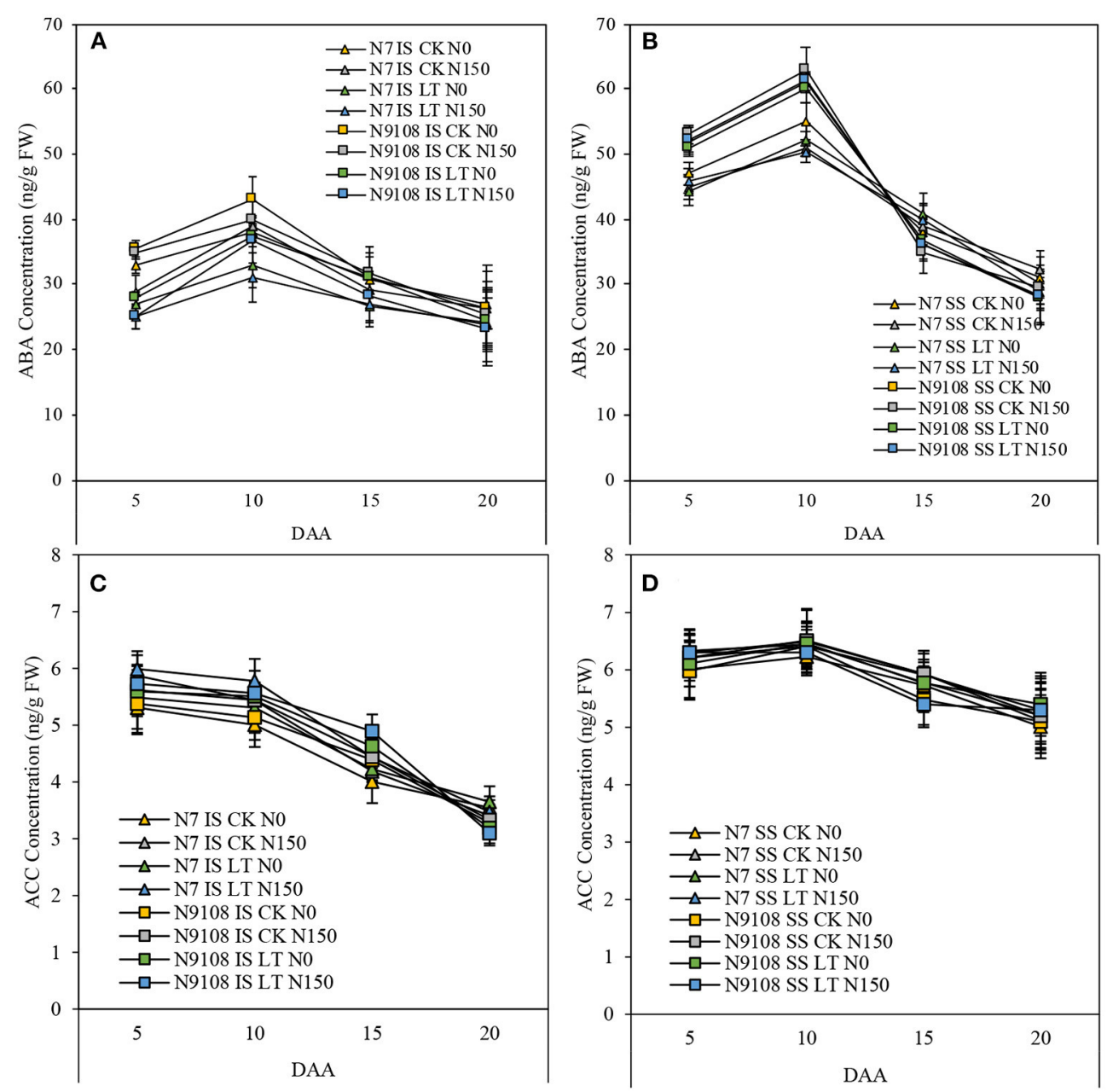

FIGURE 6 | Key hormones related to grain filling such as: Abscisic acid (ABA) and 1-aminocyclopropane-1-carboxylic acid (ACC) in IS and SS of two rice varieties (N7 and N9108) under different nitrogen panicle fertilizer (N150, Applying NPF treatment; NO, without applying NPF treatment) and filling stage temperature treatments (CK and LT). Values are means $( \pm S D)$ of three replicates. Samples were taken at 5 DAA, 10 DAA, 15 DAA, and 20 DAA. (A) ABA concentration dynamics of IS in N7 and N9108, respectively; (B) ABA concentration dynamics of SS in N7 and N9108, respectively; (C) ACC content dynamics of IS in N7 and N9108, respectively; (D) ACC content dynamics of SS in N7 and N9108, respectively.

previous study also showed that abiotic stresses affected the grain filling level by controlling starch biosynthesis (Wang et al., 2019). Compared to LT treatment, grain yield could be more significantly regulated by the NPF application in CK condition due to their insufficient filling rate (Table 3 ). The grain filling rate was reduced by individual LT treatment $(15 \pm 2.9 \%)$. Moreover, the grain filling rate was further reduced $(23 \pm 4.6 \%)$ by applying NPF simultaneously (Table 4 and Figures 2, 3). It could be concluded that higher NPF's yield increasing effect was found in CK condition compared to that in LT condition, which indicated that the appropriate NPF should be selected in LT condition.

\section{Sink Activity Controls Rice Grain Filling Rate}

The grain-filling issue in inferior spikelets proved to be more serious in the newly bred "super rice" cultivars, although they generally show $8-20 \%$ higher yield potential than other conventional rice cultivars due to their large sink size (Kato, 2004; Cheng et al., 2007; Zhang et al., 2007). For example, 12 "super rice" cultivars in the lower Yangtze River basin were investigated in 2006 and 2007, and it was found that the average grain weight and filling proportion of inferior spikelets were 20.9 and $20.7 \%$, respectively, lower than those of superior spikelets, while for three conventional cultivars, on average, it was only 10.5 and $6.3 \%$, respectively. In this study, analyzing the balance between the positive and negative effects of NPF and LT on yield formation indicated that their negative effect on grain weight formation could be more serious than the reduction of grain yield (Table 4 and Figure 1). Thus, we further investigated the grain filling rate among all treatments (Figure 1 and Table 4). The major limitation factor of different grain-filling of super rice varieties with similar sink capacity was assumed as their differential sink activities and carbohydrate supply (Yang, 2010; Yang and Zhang, 2010). In this study, significantly lower sucrose to starch conversion was found in both LT and NPF treatments, which means that sink activity could be the major controlling factor of rice grain weight (Figure 2), similar to a previous 
study (Yoshida, 1972; Kato and Takeda, 1996; Liang et al., 2001; Ishimaru et al., 2003; Yang A. et al., 2004). The sink activity could be represented by the starch biosynthesis efficiency in rice grains (Kato et al., 2007). In this study, the reduction of grain filling level in response to NPF or LT treatments were only found in the inferior seed rather than in both inferior and superior seeds, similar to the result of Wang et al. (2019). However, unlike that of environmental factors (filling stage temperature or fertilizer), the major controlling factor of grain weight between different varieties was their grain filling rate of both inferior and superior (Table 4). The grain filling rates of N9108 with superior and inferior grains were $15 \pm 4.3$ and $33 \pm 11.6 \%$ faster than that of N7, respectively, due to its higher sink activity. Unlike previous study, higher gene expression and starch accumulation was found in both inferior and superior seeds of N7 compared to that of N9108 (Table 4 and Figures 2, 3) which is closely related to higher filling rate and weight in N9108 (Table 4). Therefore, it can be concluded that (1) The sink activities of superior and inferior seeds are the major limiting factors among different varieties' grain filling levels, and (2) the environmental factors (like NPF and LT in this study) mainly affects inferior seeds.

\section{NPF and LT Suppressed Grain Filling Related Characteristics}

In the process of starch accumulation, more than 30 major enzymes participate in the metabolism of carbohydrates during endosperm development in rice. Among them, several enzymes play important roles in this process, namely, ADPglucose pyrophosphorylase, granule bound starch synthetase, soluble starch synthase, starch branching enzyme, and starch phosphorylase (Yang et al., 2001a,b; Yang J. et al., 2004; Hannah and James, 2008; Chen and Bao, 2017). The activities of these enzymes are closely related to total starch, amylose, and amylopectin accumulation in rice endosperm. To clarify the underlying regulating molecular mechanism, the genes expression of FLO4, SBE1, and PHO-l were measured and demonstrated as heatmap in this study (Figure 3). Enzymes involved in starch accumulation are not only affected by genotype but also by the growing environment of rice (Yang, 2001; Yang J. et al., 2004; Halford et al., 2015; Mayer et al., 2016). Many previous studies found that abiotic factors could affect enzyme activity and subsequently, change total starch, amylose, and amylopectin contents (Pan, 1999; Sun et al., 2018; Cheng et al., 2019; Prathap et al., 2019). Among these factors, enzyme activities are sensitive to environmental factors (like nitrogen fertilizer and temperature), and they can, consequently, affect starch accumulation (Cao et al., 2015; Fu et al., 2019), which is consistent with our results in which the gene expression was suppressed by LT and NPF (Figure 3). In this study, the lower gene expression of enzymes related to starch biosynthesis under NPF and LT treatments further reduced the amount of starch synthesis (Figures 1-3 and Table 4) which resulted in the reduced grain yield of both varieties (Table 3). Application of individual NPF and LT treatments decreased the inferior grain weight for about 13 and $21 \%$, respectively, of both varieties, which is similar to previous studies (Mae, 1997; Samonte et al., 2006), while synergistic NPF and LT treatment decreased the inferior grain weight for about 27\% (Table 3). The additive and negative effects of NPF and LT treatments could be concluded based on the above results.

Many studies have demonstrated that hormonal changes at the whole-plant level can regulate senescence and nutrient remobilization (Davies, 1995; Lee and Masclaux-Daubresse, 2021). Abiotic stresses also affect hormonal levels, potentially regulating seed development and nutrient mobility (Ober et al., 1991; Davies, 1995; Wang et al., 2006). To further investigate the variation of grain filling and related characteristics, regulative phytohormones content was measured (Figure 6). Ethylene and $\mathrm{ABA}$ are two of the major phytohormones induced in response to stress, and their content showed complex changing pattern to biotic and abiotic stresses (Davies and Zhang, 1991; Gazzarrini and Mccourt, 2001; Yang et al., 2001b, 2006; Davies et al., 2002; Wilkinson and Davies, 2002; Cheng and Lur, 2010). It was found that activities of three key enzymes involved in the sucroseto-starch pathway in the grains. SuSase, AGPase, and SSSase (Hawker and Jenner, 1993; Ahmadi and Baker, 2001; Hurkman et al., 2003), were significantly enhanced by the application of $\mathrm{ABA}$, while ethylene played an inhibitive role in grain filling, since ethylene proved to be a negative regulator of ABA action in the seed (Ghassemian et al., 2000). Many previous studies have also described the interaction between ABA and ethylene in inferior seeds and the relationship between this interaction and starch accumulation pathway (Mohapatra et al., 1993; Kato et al., 2007; Zhu et al., 2011; Zhang et al., 2012; Wang et al., 2015). It was proved by Yang et al. (2006) that higher ABA concentration and lower ACC concentration could improve the grain-filling. In this study, we measured the concentration of $\mathrm{ABA}$ and $\mathrm{ACC}$ and found that the concentration of ABA was reduced by LT and NPF, while ACC was mainly enhanced by $\mathrm{NPF}$. The result showed that the ratio of ABA and ACC was reduced by LT and NPF, which plays a negatively regulative role in the grain filling process and is consistent with grain filling changing pattern (Figure 6). One of the probable explanations of reduced grain filling in this study is the ratio of $A B A$ and ACC. However, the biosynthesis and catabolism of ABA and ethylene in responding to LT and NPF are still unclear. Hence, the molecular studies on the hormones are necessary to dissect the underlying mechanism.

\section{CONCLUSION}

The result led to the conclusion that higher sink activities of super rice, namely, higher grain filling rates, which was regulated by the elevated ratio of ABA and ACC, are the major contributor of higher adaptivity to NPF and LT conditions. Moreover, the negative and additive effect of LT and NPF was also found on grain filling events of both varieties. Higher sensitivities of grain filling in response to NPF were found under LT compared to that under CK. This study provides basic knowledge about the mechanism of grain filling of different super rice cultivars with different sink activities in response to LT and NPF. 


\section{DATA AVAILABILITY STATEMENT}

The original contributions presented in the study are included in the article/Supplementary Material, further inquiries can be directed to the corresponding author/s.

\section{AUTHOR CONTRIBUTIONS}

GL contributed to conception and design of the study. CX performed organization of the database, statistical analysis, and manuscript writing. All authors contributed to manuscript revision, read, and approved the submitted version.

\section{REFERENCES}

Ahmadi, A., and Baker, D. (2001). The effect of water stress on the activities of key regulatory enzymes of the sucrose to starch pathway in wheat. Plant Growth Regul. 35, 81-91. doi: 10.1023/A:1013827600528

Ao, H., Wang, S., Zou, Y., Peng, S., Tang, Q., Fang, Y., et al.. (2008). Study on yield stability and dry matter characteristics of super hybrid rice. Sci. Agric. Sin. 41, 1927-1936.

Cao, N., Xiong, Q., Xiao, R., He, H., Zhu, C., Fu, J., et al. (2018). Effects of different nitrogen application rates on low temperature resistance of late rice at heading and flowering stage (in Chinese). J. Appl. Ecol. 29, 2566-2574. doi: 10.13287/j.1001-9332.201808.022

Cao, Z., Pan, G., Wang, F., Wei, K., Li, Z., Shi, C., et al. (2015). Effect of high temperature on the expressions of genes encoding starch synthesis enzymes in developing rice endosperms. J. Integr. Agric. 14, 642-659. doi: 10.1016/S2095-3119(14)60782-6

Chen, T., Xu, Y., Wang, J., Wang, Z., Yang, J., and Zhang, J. (2013). Polyamines and ethylene interact in rice grains in response to soil drying during grain filling. J. Exp. Bot. 64, 2523-2538. doi: 10.1093/jxb/ert115

Chen, Y., and Bao, J. (2017). Progress in structures, functions and interactions of starch synthesis related enzymes in rice endosperm. Chin. J. Rice Sci. 31. doi: 10.16819/j.1001-7216.2017.6132

Cheng, C., and Lur, H. (2010). Ethylene may be involved in abortion of the maize caryopsis. Physiol. Plant. 98, 245-252. doi: 10.1034/j.1399-3054.1996. 980205.x

Cheng, C., Zeng, Y., Chen, H., Tan, X., Shan, Q., Zeng, Y., et al. (2019). Effects of different temperature from full heading to milking on grain filling stage on grain hormones concentrations, activities of enzymes involved in starch synthesis and accumulation in rice Nanjing 9108 (in Chinese with English abstract). Chin. J. Rice Sci. 33, 57-67. doi: 10.16819/j.1001-7216.201 9.8077

Cheng, S., Zhuang, J., Fan, Y., Du, J., and Cao, L. (2007). Progress in research and development on hybrid rice: a super-domesticate in China. Ann. Bot. 100, 959-966. doi: 10.1093/aob/mcm 121

Davies, P. (1995). Plant Hormones Physiology, Biochemistry and Molecular Biology, 2nd Edn. Dordrecht: Kluwer Academic Publishers.

Davies, W., Wilkinson, S., and Loveys, B. (2002). Stomatal control by chemical signalling and the exploitation of this mechanism to increase water use efficiency in agriculture. New Phytol. 153, 449-460. doi: 10.1046/j.0028-646X.2001.00345.x

Davies, W., and Zhang, J. (1991). Root signals and the regulation of growth and development of plants in drying soil. Annu. Rev. Plant Physiol. Plant Mol. Biol. 42, 55-76. doi: 10.1146/annurev.pp.42.060191.000415

Ding, C., Luo, X., Wu, Q., Lu, B., Wang, S., Ding, Y., et al. (2020). Compact plant type rice has higher lodging and $\mathrm{N}$ resistance under machine transplanting. J. Integr. Agric. 19, 2-13. doi: 10.1016/S2095-3119(20)63229-4

Ding, C., You, J., Chen, L., Wang, S., and Ding, Y. (2014). Nitrogen fertilizer increases spikelet number per panicle by enhancing cytokinin synthesis in rice. Plant Cell. Rep. 33, 363-371. doi: 10.1007/s00299-013-1536-9

\section{FUNDING}

This work was supported by the National Key Research and Development Program of China (2018YFD0300803, 2017YFD0300100, and 2017YFD0301204), Key Research and Development Program of Jiangsu Province (BE2017369), and the Jiangsu Agriculture Science and Technology Innovation Fund [CX(18)1002].

\section{SUPPLEMENTARY MATERIAL}

The Supplementary Material for this article can be found online at: https://www.frontiersin.org/articles/10.3389/fpls.2021. 729021/full\#supplementary-material

Ding, Y., Liu, Y., and Wang, Z. (2010). Effects of panicle nitrogen fertilization on non-structural carbohydrate and grain filling in indica rice (in Chinese). Agric. Sci. China. 2010, 1630-1640. doi: 10.1016/S1671-2927(09) 60260-1

Ding, Y., Zhao, C., and Wang, Q. (2003). Effect of application stage of panicle fertilizer on rice grain yield and the utilization of nitrogen (in Chinese). $J$. Nanjing Agric. Univ. 26, 5-8.

Duan, M., and Sun, S. (2005). Profiling the expression of genes controlling rice grain quality. Plant Mol. Biol. 59:165. doi: 10.1007/s11103-004-7507-3

Fageria, N., and Santos, A. (2015). Yield and yield components of lowland rice genotypes as influenced by nitrogen fertilization. Commun. Soil Sci. Plant Anal. 46, 1723-1735. doi: 10.1080/00103624.2015.1043443

Fu, P., Wang, J., and Zhang, T. (2019). High nitrogen input causes poor grain filling of spikelets at the panicle base of super hybrid rice. Field Crops Res. 244:107635. doi: 10.1016/j.fcr.2019.107635

Gazzarrini, S., and Mccourt, P. (2001). Genetic interactions between aba, ethylene and sugar signaling pathways. Curr. Opin. Plant Biol. 4, 387-391. doi: 10.1016/S1369-5266(00)00190-4

Ghassemian, M., Nambara, E., Cutler, S., Kawaide, H., and Mccourt, K. (2000). Regulation of abscisic acid signaling by the ethylene response pathway in Arabidopsis. Plant Cell. 12, 1117-1126. doi: 10.1105/tpc.12.7.1117

Halford, N., Curtis, T., Chen, Z., and Huang, J. (2015). Effects of abiotic stress and crop management on cereal grain composition: implications for food quality and safety. J. Exp. Bot. 66, 1145-1156. doi: 10.1093/jxb/eru473

Hannah, L., and James, M. (2008). The complexities of starch biosynthesis in cereal endosperms. Curr. Opin. Biotechnol. 19, 160-165. doi: 10.1016/j.copbio.2008.02.013

Hawker, J., and Jenner, C. (1993). High temperature affects the activity of enzymes in the committed pathway of starch synthesis in developing wheat endosperm. Aust. J. Plant Physiol. 20, 197-209. doi: 10.1071/PP9930197

He, Z. (1985). Grain Quality and Its Analysis Technology (in Chinese). Beijing: Agricultural Press.

Ho, L. (1988). Metabolism and compartmentation of imported sugars in sink organs in relation to sink strength. Annu. Rev. Plant Biol. 39, 355-378. doi: 10.1146/annurev.pp.39.060188.002035

Horie, T., Shiraiwa, T., Homma, K., Katsura, K., Mae Da, S., and Yoshida, H. (2005). Can yields of lowland rice resume the increases that they showed in the 1980s? Plant Prod. Sci. 8, 259-274. doi: 10.1626/pps.8.259

Hurkman, W., McCue, K., Altenbach, S., Korn, A., Tanaka, C., Kothari, K., et al. (2003). Effect of temperature on expression of genes encoding enzymes for starch biosynthesis in developing wheat endosperm. Plant Sci. 164, 873-881. doi: 10.1016/S0168-9452(03)00076-1

Ishimaru, T., Matsuda, T., Ohsugi, R., and Yamagishi, T. (2003). Morphological development of rice caryopses located at the different positions in a panicle from early to middle stage of grain filling. Funct. Plant Biol. 30, 1139-1149. doi: 10.1071/FP03122

Jacobs, B., and Pearson, C. (2010). Growth, development and yield of rice in response to cold temperature. J. Agron. Crop Sci. 182, 79-88. doi: 10.1046/j.1439-037x.1999.00259.x 
Jia, Y., Wang, J., Qu, Z., Zou, D., and Zhao, H. (2019). Effects of low water temperature during reproductive growth on photosynthetic production and nitrogen accumulation in rice. Field Crops Res. 242:107587. doi: 10.1016/j.fcr.2019.107587

Jiang, Q., Du, Y., Tian, X., Wang, Q., Xiong, R., Xu, G., et al. (2016). Effect of panicle nitrogen on grain filling characteristics of high-yielding rice cultivars. Eur. J. Agron. 74, 185-192. doi: 10.1016/j.eja.2015.11.006

Kato, T. (2004). Effect of spikelet removal on the grain filling of Akenohoshi, a rice cultivar with numerous spikelets in a panicle. J. Agr. Sci. Cambridge 142, 177-181. doi: 10.1017/S0021859604004265

Kato, T., Shinmura, D., and Taniguchi, A. (2007). Activities of enzymes for sucrosestarch conversion in developing endosperm of rice and their association with grain filling in extra-heavy panicle types. Plant Prod. Sci. 10:442-450. doi: $10.1626 /$ pps. 10.442

Kato, T., and Takeda, K. (1996). Associations among characters related to yield sink capacity in space-planted rice. Crop Sci. 36, 1135-1139. doi: $10.2135 /$ cropsci1996.0011183X003600050011x

Khush, G. S. (2013). Strategies for increasing the yield potential of cereals: case of rice as an example. Plant Breed. 132, 433-436. doi: 10.1111/pbr.1991

Kirk, G., George, T., Courtois, B., and Senadhira, D. (1997). Opportunities to improve phosphorus efficiency and soil fertility in rainfed lowland and upland rice ecosystems. Field Crops Res. 56, 73-92. doi: 10.1016/S0378-4290(97)00141-X

Lee, S., and Masclaux-Daubresse, C. (2021). Current understanding of leaf senescence in rice. Int. J. Mol. Sci. 22:4515. doi: 10.3390/ijms22094515

Liang, J., Zhang, J., and Cao, X. (2001). Grain sink strength may be related to the poor grain filling of indica-japonica rice (Oryza sativa) hybrids. Physiol. Plant. 112, 470-477. doi: 10.1034/j.1399-3054.2001.1120403.x

Mae, T. (1997). Physiological nitrogen efficiency in rice: nitrogen utilization, photosynthesis, and yield potential. Plant Soil 196, 201-210. doi: 10.1023/A:1004293706242

Mayer, L., Savin, R., and Maddonni, G. (2016). Heat stress during grain filling modifies kernel protein composition in field-grown maize. Crop Sci. 56, 1890-1903. doi: 10.2135/cropsci2015.09.0537

Mohapatra, P., Patel, R., and Sahu, S. (1993). Time of flowering affects grain quality and spikelet partitioning with in the rice panicle. Aust. J. Plant Physiol. 20, 231-242. doi: 10.1071/PP9930231

National Bureau of Statistics of China (2015). China Statistical Yearbook. Beijing: China Statistics Press.

Ober, E., Setter, T., Madison, J., Thompson, J., and Shapiro, P. (1991). Influence of water deficit on maize endosperm development. Enzyme activities and RNA transcripts of starch and zein synthesis, abscisic acid, and cell division. Plant Physiol. 97, 154-164. doi: 10.1104/pp.97.1.154

Ohnishi, M., Horie, T., Homma, K., Supapoj, N., Takano, H., and Yamamoto, S. (1999). Nitrogen management and cultivar effects on rice yield and nitrogen use efficiency in Northeast Thailand. Field Crops Res. 64, 109-120. doi: 10.1016/S0378-4290(99)00054-4

Pan, X. (1999). Starch accumulation and changes in enzyme activities involved in starch synthesis during the development of rice endosperm (in Chinese). Acta Agric. Univ. Jiangxiensis 21, 456-462.

Panda, B., Sekhar, S., Dash, S., Behera, L., and Shaw, B. (2018). Biochemical and molecular characterization of exogenous cytokinin application on grain filling in rice. BMC Plant Biol. 18:89. doi: 10.1186/s12870-018-1279-4

Patindol, J., Siebenmorgen, T., and Wang, Y. (2015). Impact of environmental factors on rice starch structure: a review. Starch 67, 42-54. doi: 10.1002/star.201400174

Peng, S. (2016). Dilemma and way-out of hybrid rice during the transition period in China. Acta Agron. Sin. 42, 313-319. doi: 10.3724/SP.J.1006.2016.00313

Peng, S., Cassman, G., Virmani, S., Sheehy, J., and Khush, G. (1999). Yield potential trends of tropical since the release of IR8 and its challenge of increasing rice yield potential. Crop Sci. 39, 1552-1559. doi: 10.2135/cropsci1999.3961552x

Peng, S., Khush, G. S., Virk, P., Tang, Q., and Zou, Y. (2008). Progress in ideotype breeding to increase rice yield potential. Field Crops Res. 108, 32-38. doi: 10.1016/j.fcr.2008.04.001

Prathap, V., Ali, K., Singh, A., Vishwakarma, C., Krishnan, V., Chinnusamy,. V., et al. (2019). Starch accumulation in rice grains subjected to drought during grain filling stage. Plant Physiol. Biochem. 142, 440-451. doi: 10.1016/j.plaphy.2019.07.027
Qiu, Z., Kong, P., Yu, C., Huang, G., Chen, H., Lei, J., et al. (2016). Study on the occurrence regularity of cold stress and rice cropping system in jiangxi province (in Chinese). China Rice. 22, 20-26. doi: 10.3969/j.issn.1006-8082.2016. 05.005

Samonte, S., Wilson, L., and James, C. (2006). Nitrogen utilization efficiency: relationships with grain yield, grain protein and yield-related traits in rice. Agron. J. 98, 168-176. doi: 10.2134/agronj2005.0180

Singh, N., Pal, N., Mahajan, G., Singh, S., and Shevkani, K. (2011). Rice grain and starch properties: effects of nitrogen fertilizer application. Carbohydr Polym. 86, 219-225. doi: 10.1016/j.carbpol.2011.04.039

Sipaseuth., Basnayake, J., Fukai, S., Farrell, T., C., Senthonghae, M., et al. (2007). Opportunities to increasing dry season rice productivity in low temperature affected areas. Field Crops Res. 102, 87-97. doi: 10.1016/j.fcr.2007. 03.001

Sun, T., Tong, L., Zhao, S., Wang, H., Han, Y., Zhang, Z., et al. (2018). Effects of nitrogen fertilizer application on starch quality, activities and gene expression levels of related enzymes in rice endosperm (in Chinese with English abstract). Chin. J. Rice Sci. 32, 475-484. doi: 10.16819/j.1001-7216.2018.8013

Van Loon, M., Feike, S., Max, R., Stefan, C., Frank, S., and Niels, P. (2014). How light competition between plants affects their response to climate change. New Phytol. 203, 1253-1265. doi: 10.1111/nph.12865

Venkateswarlu, B., and Visperas, R. M. (1987). Source-Sink Relationships in Crop Plants. Los Banos: IRRI Research Paper Series, 125.

Wang, E., Wang, J., Zhu, X., Hao, W., Wang, L., Li, Q., et al. (2008). Control of rice grain-filling and yield by a gene with a potential signature of domestication. Nat. Genet. 40, 1370-1374. doi: 10.1038/ng.220

Wang, F., Cheng, F., and Zhang, G. (2006). The relationship between grain filling and hormone content as affected by genotype and source-sink relation. Plant Growth Regul. 49, 1-8. doi: 10.1007/s10725-006-0017-3

Wang, G., Hao, S., Gao, B., Chen, M., Liu, Y., Yang, J., et al. (2017). Regulation of gene expression in the remobilization of carbon reserves in rice stems during grain filling. Plant Cell Physiol. 58, 1391-1404. doi: 10.1093/pcp/pcx072

Wang, G., Li, H., Feng, L., Chen, M., Meng, S., Ye, N., et al. (2019). Transcriptomic analysis of grain filling in rice inferior grains under moderate soil drying. J. Exp. Bot. 5, 1597-1611. doi: 10.1093/jxb/erz010

Wang, W., Cui, W., Ke, X., Gao, H., Wei, H., and Zhang, H. (2021). Effects of early- and late-sowing on starch accumulation and associated enzyme activities during grain filling stage in rice. Rice Sci. 28:9. doi: 10.1016/j.rsci.2021.01.008

Wang, X., Tao, L., Yu, M., and Huang, X. (2002). Physiological model of super hybrid rice Xieyou 9308. Chin. J. Rice Sci. 38-44.

Wang, Z., Xu, Y., Chen, T., Zhang, H., Yang, J., and Zhang, J. (2015). Abscisic acid and the key enzymes and genes in sucrose-to-starch conversion in rice spikelets in response to soil drying during grain filling. Planta 241, 1091-1107. doi: 10.1007/s00425-015-2245-0

Wilkinson, S., and Davies, W. (2002). ABA-based chemical signaling: the coordination of responses to stress in plants. Plant Cell Environ. 25, 195-210. doi: 10.1046/j.0016-8025.2001.00824.x

Xing, Z., Cao, W., Qian, H., Hu, Y., Zhang, H., Dai, Q., et al. (2016). Effect of sowing date on the formation of quality of mechanically transplanted rice in rice-wheat cropping areas (in Chinese). Chin. J. Ecol. 35, 1-10. doi: 10.13292/J.1000-4890.201601.001

Yang, A., Mu, X., Li, M., Ye, M., and Yu, H. (2004). Effect of nitrogen application on the senescence of flag leaf and yield of rice cultivated in aerobic soil. J. Nanjing Agric. Univ. 27, 126-129. doi: 10.1300/J064v24n01_09

Yang, J. (2001). Changes in activities of three enzymes associated with starch synthesis in rice grains during grain filling. Acta Agron. Sin. 27, 157-164. doi: 10.3321/j.issn:0496-3490.2001.02.004

Yang, J. (2010). Mechanism and regulation in the filling of inferior spikelets of rice. Acta Agron. Sin. 36:12. doi: 10.3724/SP.J.1006.2010.02011

Yang, J., Peng, S., Zhang, Z., Wang, Z., Visperas, R., and Zhu, Q. (2002). Grain and dry matter yield and partitioning of assimilates in japonica/indica hybrids. Crop Sci. 42, 766-772. doi: 10.2135/cropsci2002.0766

Yang, J., and Zhang, J. (2010). Grain-filling problem in "super" rice. J. Exp. Bot. 61, 1-5. doi: $10.1093 / \mathrm{jxb} / \mathrm{erp} 348$

Yang, J., Zhang, J., Liu, K., Wang, Z., and Liu, L. (2006). Abscisic acid and ethylene interact in wheat grains in response to soil drying during grain filling. New Phytol. 171, 293-303. doi: 10.1111/j.1469-8137.2006. 01753.x 
Yang, J., Zhang, J., Wang, Z., Xu, G., and Zhu, Q. (2004). Activities of key enzymes in sucrose-to-starch conversion in wheat grains subjected to water deficit during grain filling. Plant Physiol. 135, 1621-1629. doi: 10.1104/pp.104. 041038

Yang, J., Zhang, J., Wang, Z., and Zhu, Q. (2001a). Activities of starch hydrolytic enzymes and sucrose-phosphate synthase in the stems of rice subjected to water stress during grain filling. J. Exp. Bot. 52, 2169-2179. doi: $10.1093 /$ jexbot/52.364.2169

Yang, J., Zhang, J., Wang, Z., Zhu, Q., and Wang, W. (2001b). Hormonal changes in the grains of rice subjected to water stress during grain filling. Plant Physiol. 127, 315-323. doi: 10.1104/pp.127.1.315

Yang, J., Zhang, J., Wang, Z., Zhu, Q., and Wei, W. (2001c). Remobilization of carbon reserves in response to water deficit during grain filling of rice. Field Crops Res. 71, 47-55. doi: 10.1016/S0378-4290(01) 00147-2

Yang, W., Peng, S., Dionisio-Sese., Laza, R., and Visperas, R. (2008). Grain filling duration, a crucial determinant of genotypic variation of grain yield in field-grown tropical irrigated rice. Field Crops Res. 105, 221-227. doi: 10.1016/j.fcr.2007.10.006

Yoshida, S. (1972). Physiological aspects of grain yield. Annu. Rev. Plant Physiol. 23, 437-464. doi: 10.1146/annurev.pp.23.060172.002253

Yoshida, S., and Hara, T. (1977). Effects of air temperature and light on grain filling of an indica and a japonica rice (Oryza sativa L.) under controlled environmental conditions. J. Soil Sci. Plant Nutr. 23, 93-107. doi: 10.1080/00380768.1977.10433026

Zhang, J., Li, Y., and Liu, J. (2008). Effects of nitrogen on starch accumulation and activities of enzymes involved in starch synthesis in rice caryopsis: effects of nitrogen on starch accumulation and activities of enzymes involved in starch synthesis in rice caryopsis. Acta Agron. Sin. 34, 2168-2175. doi: 10.3724/SP.J.1006.2008.02168

Zhang, J., Zhang, Y., Song, N., Chen, Q., and Zhao, Q. (2021). Response of grainfilling rate and grain quality of mid-season indica rice to nitrogen application. J. Integr. Agric. 20, 1465-1473. doi: 10.1016/S2095-3119(20)63311-1

Zhang, Y., Ding, Y., Wang, Q., Li, G., Li, F., and Wang, S. (2007). Effect of panicle nitrogen fertilizer on quality properties of different rice varieties (in Chinese). Plant Nutr. Fertilizer Sci. 13, 1080-1085. doi: 10.3964/j.issn.1000-0593(2015)03-0746-05
Zhang, Z., Chen, J., Lin, S., Zhong, L., Cheng, R., and Fang, C., et al. (2012) Proteomic and phosphoproteomic determination of ABA's effects on grainfilling of Oryza sativa L. inferior spikelets. Plant Sci. 185-186, 259-273. doi: 10.1016/j.plantsci.2011.11.012

Zhao, B., Zhang, W., Zhang., Zhu, Q., and Yang, J. (2004). Changes in activities of key enzymes related to starch synthesis in rice grains during grain filling and their relationships with the filling rate and cooking quality. Agric. Sci. China 37, 1123-1129. doi: 10.1016/S0140-6736(01)95101-3

Zhu, C., Shen, W., Zhai, H., and Wan, J. (2004). Advances in researches of the application of low-amylose content rice gene for breeding. Sci. Agric. Sin 37, 157-162. doi: 10.3321/j.issn:0578-1752.2004.02.001

Zhu, G., Ye, N., Yang, J., Peng, X., and Zhang, J. (2011). Regulation of expression of starch synthesis genes by ethylene and aba in relation to the development of rice inferior and superior spikelets. J. Exp. Bot. 62, 3907-3916. doi: $10.1093 / \mathrm{jxb} / \mathrm{err} 088$

Zou, Y., and Huang, M. (2018). Opportunities and challenges for crop production in China during the transition period. Acta Agron. Sin. 44:791. doi: 10.3724/SP.J.1006.2018.00791

Conflict of Interest: The authors declare that the research was conducted in the absence of any commercial or financial relationships that could be construed as a potential conflict of interest.

Publisher's Note: All claims expressed in this article are solely those of the authors and do not necessarily represent those of their affiliated organizations, or those of the publisher, the editors and the reviewers. Any product that may be evaluated in this article, or claim that may be made by its manufacturer, is not guaranteed or endorsed by the publisher.

Copyright (C) $2021 \mathrm{Xu}$, Yang, Tang, Lu, Li, Liu, Ding, Ding and Li. This is an openaccess article distributed under the terms of the Creative Commons Attribution License (CC BY). The use, distribution or reproduction in other forums is permitted, provided the original author(s) and the copyright owner(s) are credited and that the original publication in this journal is cited, in accordance with accepted academic practice. No use, distribution or reproduction is permitted which does not comply with these terms. 